\title{
Aerogels: promising nanostructured materials for energy conversion and storage applications
}

\author{
S. Alwin ${ }^{1,2} \cdot$ X. Sahaya Shajan ${ }^{1}$
}

Received: 1 January 2020 / Accepted: 30 March 2020 / Published online: 6 April 2020

(c) The Author(s) 2020

\begin{abstract}
Aerogels are 3-D nanostructures of non-fluid colloidal interconnected porous networks consisting of loosely packed bonded particles that are expanded throughout its volume by gas and exhibit ultra-low density and high specific surface area. Aerogels are normally synthesized through a sol-gel method followed by a special drying technique such as supercritical drying or ambient pressure drying. The fascinating properties of aerogels like high surface area, open porous structure greatly influence the performances of energy conversion and storage devices and encourage the development of sustainable electrochemical devices. Therefore, this review describes on the applications of inorganic, organic and composite aerogel nanostructures to dye-sensitized solar cells, fuel cells, batteries and supercapacitors accompanied by the significant steps involved in the synthesis, mechanism of network formation and various drying techniques.
\end{abstract}

Keywords Mesoporous materials $\cdot$ Nanostructure $\cdot$ Network $\cdot$ Composite $\cdot$ Aerogel $\cdot$ Graphene

\section{Introduction}

The demand for energy in these days is extremely high as the consumption is increasing steeply due to the increase in world population and industrialization [1]. According to the international energy outlook 2018 (IEO2018), the projected energy requirement for the entire world in 2020 is $178 \times 10^{9} \mathrm{MWh}$ and which will increase to $193 \times 10^{10} \mathrm{MWh}$ in 2030. Presently, most of the energy demand is supplied by fossil fuels such as coal, oil and natural gas. However, the depletion of these fuels and the environmental pollutions associated with their refinement processes have encouraged the development of sustainable and environmentally benign energy technology [2]. To address growing global energy demand, sustainable energy technology is needed to reduce fossil fuel dependence, environmental impact and the cost. Besides, it is possible to decrease the emissions and waste by

X. Sahaya Shajan

shajan89@gmail.com

1 Center for Scientific and Applied Research, PSN College of Engineering and Technology (An Autonomous Institution Affiliated to Anna University, Chennai), Melathediyoor, Tirunelveli, Tamil Nadu 627152, India

2 Department of Chemistry, V.S.B. Engineering College, Karur, Tamil Nadu 639111, India adopting clean energy technology in our day to day life [3, 4]. Accordingly, solar cells, fuel cells, rechargeable lithium batteries, supercapacitors and photocatalytic water splitting were extensively studied, so as to get high-performance energy conversion and storage devices [5]. The innovations and breakthroughs happening in materials chemistry play a vital role in enhancing the performance of these devices [6]. Particularly, nanotechnology and nanomaterials have the potential to make cost-effective and high-performance devices for realizing the objective of renewable and sustainable energy technologies [7].

The development of nanostructured materials has received much attention due to their interesting physical and chemical properties as the size becomes smaller and smaller to nanometer scale. Consequently, 0-, 1-, 2- and 3-dimensional nanostructures such as nanospheres, nanoparticles, nanotubes, nanorods, nanowires, nanosheets and interconnected network structures were reported for different applications. 1-D nanostructures such as rods, wires and tubes, are well-known for transport properties but the low surface area of one-dimensional nanostructures limits their application in many fields [8]. Therefore, 3-D nanostructures are extensively studied in recent years, in which lower-dimensional nanomaterials are anisotropically arranged in a 3-D manner and forms an interconnected network structure. The 3-D interconnected network structure offers large internal 
surface area, high carrier mobility, ultra-low density and high interfacial area. Also, excessive porosity and tunable pore sizes assist in accommodating bulky molecules and reactants to improve performance [9].

Aerogels are one such fascinating 3-D nanostructures of non-fluid, colloidal, interconnected, porous networks consisting of loosely packed bonded particles that is expanded throughout its volume by gas and exhibit ultra-low density and high specific surface area. Aerogels are derived from wet gels when the pore liquid is replaced by air and the interconnected network structure is retained without any shrinkage. The electron microscopic images of the porous, continuous network structure of aerogels are shown in Fig. 1. Therefore, aerogels are airy materials i.e. $95 \%$ of the volume is occupied by air and their density is exceptionally low [10]. In addition, aerogels are considered to be a new state of matter, an intermediate state between liquid and gas, since the density of aerogel is between liquid and gaseous state [11]. Indeed, the popularity of the aerogel was continuously increased after they have been used in space applications [12].

Aerogels were employed as particle detectors and cosmic dust collectors in space applications due to their extraordinarily low refractive index. They have the lowest thermal conductivities of all solids which make this material as a best thermal insulator. The above applications of aerogel nanostructures were reviewed well by Lawrence [13]. Also, aerogel based drug delivery systems were reviewed by Ulker et al. [14]. The applications of aerogel nanostructures were extended to various energy conversion and storage devices such as dye-sensitized solar cells, water splitting, batteries, fuel cells and supercapacitors in recent times. As far as energy conversion and storage devices are concerned, adsorption and ionic mobility are very crucial properties for the fabrication of high-performance electrochemical energy devices. Accordingly, the beneficial physical and chemical properties offered by aerogel nanostructures are considered to be imperative for energy conversion and storage applications. The high specific surface area of aerogel provides more space for molecular adsorption at the solid-liquid interface and the open porous structure facilitates ionic mobility and electrolyte diffusion for fabricating highperformance energy conversion and storage devices. For instance, the adsorption of large dye molecules on the semiconductor surface and electrolyte diffusion at the interface is very important for dye-sensitized solar cells [15]. Likewise, the accumulation of charges on the surface is valuable for supercapacitor applications and Li-ion mobility is significant for battery applications [16]. Besides, the modifiable surface chemistry of aerogels made these materials as attractive candidates for energy conversion and storage applications. Therefore in this review, we present an overview of the key steps involved in aerogel synthesis and mainly focuses on the applications of aerogel nanostructures to energy conversion and storage devices.

\section{Classification of aerogels}

Aerogels are classified in a number of ways based on the convenience since there is no IUPAC classification for aerogels. Based on the physical state the aerogel is classified into three types as monoliths powder and film. Based on the preparation it is classified as aerogel, xerogel, cryogel and hydrogels. However, the classification based on the composition seems to be more convenient for studying and understanding the properties of aerogels [11]. Thus, the aerogels are classified into three major categories based on their composition. They are inorganic aerogels, organic aerogels and aerogel composites. Inorganic aerogels include transition metal oxide aerogels, metallic aerogels and chalcogenide aerogels generally derived from inorganic precursor materials such as metal alkoxides or metal salts. Organic aerogels include carbon aerogels, carbon nanotube aerogels, graphene aerogels and polymeric aerogels prepared from organic precursor materials such as phenol formaldehyde resin. Composite aerogel includes mixed oxide aerogels, metal oxide-based aerogel composites, aerogel-MOF composites and carbon aerogel-based composites and other aerogel based composites prepared by the combination of both inorganic and organic precursors depending upon the
Fig. 1 Microscopic images of highly porous, continuous $3-\mathrm{D}$ network structure of aerogel layer
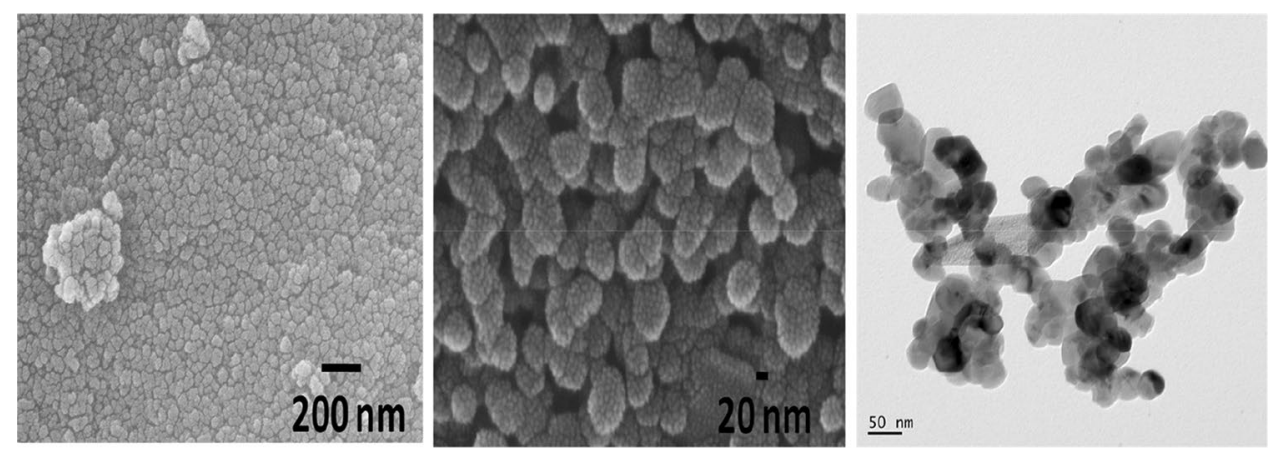
required composite aerogels. The schematic diagram of the classification of aerogel is shown in Fig. 2.

\section{Synthesis of aerogels}

The synthesis of aerogel involves the formation of primary nanoparticles or the building blocks through hydrolysis followed by the condensation of the building blocks to form a network structure and finally the removal of pore liquid without disturbing the network structure. The hydrolysis and condensation are the competing processes that occur during synthesis. In addition, the network formation and the drying are the two key steps involved in the synthesis of aerogels. Various synthetic strategies employed for the synthesis of aerogels from molecular routes, the assembly of nanoparticles and the fundamental mechanism of network formation is reviewed by Rechberger et al. [17]. Different methods adopted for synthesizing aerogel nanostructures are summarized (Table 1) in the following section.

\section{Methods}

\section{Sol-Gel method}

The most common technique used for the preparation of aerogel nanostructure is sol-gel method in which the metal alkoxides are hydrolyzed to form primary nanoparticle or the building blocks which undergo aggregation [18]. The schematic diagram of aerogel synthesis by sol-gel route from molecular precursors undergoing hydrolysis and condensation reactions is presented in Fig. 3. A colloidal suspension of solid particles with a diameter ranging from $1 \mathrm{~nm}$ to
$1 \mu \mathrm{m}$ is called sol. These colloidal particles are condensed together and form an irregular, three-dimensional network that extends through the entire volume of the solution [19]. Now, the pores of the 3-D solid network are filled with a liquid and the resulting network is called gel. The gelation process is normally initiated by changing the $\mathrm{pH}$ or temperature of the sol.

\section{Self-assembly method}

Self assembly is a potential tool for the preparation of large and complex structured systems at a macroscopic level from their molecular level building blocks [20]. It includes the isotropic assembly of 0-D nanostructures or the anisotropic assembly of 1-D or 2-D nanostructures [21]. This method was employed for the synthesis of chalcogenide aerogels such as $\mathrm{CdSe}, \mathrm{CdS}, \mathrm{ZnS}$ and $\mathrm{PbS}$ comprising the formation of naoparticle building blocks through thiolate capping and initiating the gelation through controlled surface group loss followed by supercritical drying. The study revealed that the method is an excellent strategy for the synthesis of a variety of aerogels since the resulting aerogel retains the photophysical properties of quantum confined building blocks [22]. Recently, carbonitride aerogels were synthesized by a self-assembly method without using any cross-linking agents for gelation [23]. It involves the formation of nanoparticle building blocks by temperature-induced condensation of melamine and potassium thiocyanate and self assembly without any assistance followed by freeze drying.

It is believed that the self-assembly method is a powerful tool for preparing aerogels for various functional applications. Also, this method is advantageous over sol-gel because of the high crystallinity of the final aerogel.

Fig. 2 Classification of aerogels

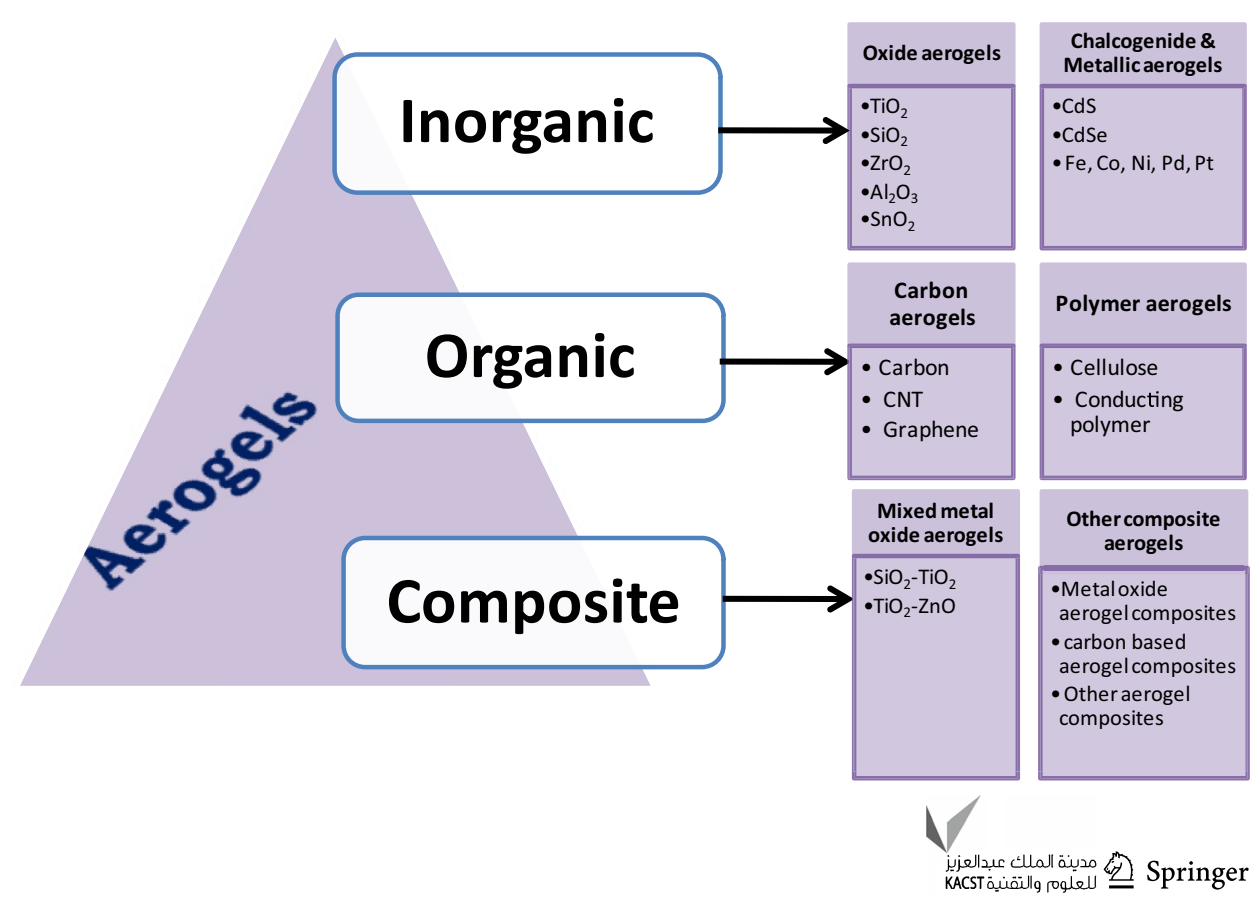


Table 1 Different methods adopted for synthesizing various aerogel nanostructures and their advantages and disadvantages

\begin{tabular}{|c|c|c|c|c|}
\hline S.No & Synthetic method & Advantages & Disadvantages & Aerogels synthesized \\
\hline 1 & Sol-Gel & $\begin{array}{l}\text { Simple and widely studied } \\
\text { Monoliths can be obtained }\end{array}$ & $\begin{array}{l}\text { Aerogels are amorphous } \\
\text { Hydrolysis and condensation are } \\
\text { very fast } \\
\text { Time consuming }\end{array}$ & $\begin{array}{l}\text { Inorganic oxide aerogels, carbon aero- } \\
\text { gels and composite aerogels }\end{array}$ \\
\hline 2 & Epoxide addition & $\begin{array}{l}\text { Hydrolysis and condensation can be } \\
\text { controlled } \\
\text { The properties of the final aerogel can } \\
\text { be tailored based on the necessity }\end{array}$ & $\begin{array}{l}\text { Aerogels obtained are amorphous } \\
\text { Time consuming }\end{array}$ & $\begin{array}{l}\mathrm{ZnO}, \mathrm{Fe}_{2} \mathrm{O}_{3}, \mathrm{Cr}_{2} \mathrm{O}_{3}, \mathrm{Co}_{3} \mathrm{O}_{4}, \mathrm{Gd}_{2} \mathrm{O}_{3}, \\
\underset{\mathrm{Ta}_{2} \mathrm{O}_{5}}{ },\end{array}$ \\
\hline 2 & Self assembly & $\begin{array}{l}\text { Large and complex structures can be } \\
\text { obtained } \\
\text { Crystalline aerogels are obtained }\end{array}$ & $\begin{array}{l}\text { Difficult to control the assembly of } \\
\text { building blocks }\end{array}$ & $\begin{array}{l}\text { Chalcogenide, Carbonitride, Inorganic } \\
\text { oxide aerogels, Metallic aerogels }\end{array}$ \\
\hline 3 & Template & $\begin{array}{l}\text { Highly crystalline aerogels are } \\
\text { obtained } \\
\text { Assembly of building blocks can be } \\
\text { controlled }\end{array}$ & $\begin{array}{l}\text { Removal of templates are difficult } \\
\text { and damages the aerogel network }\end{array}$ & Functional aerogels \\
\hline 4 & Emulsion & $\begin{array}{l}\text { Aerogels can be obtained in micro } \\
\text { spherical and other forms }\end{array}$ & Difficult to remove the emulsifier & $\begin{array}{l}\text { Polymeric and inorganic oxide aero- } \\
\text { gels }\end{array}$ \\
\hline 5 & 3-D Printing & $\begin{array}{l}\text { Hybrid and modern technique } \\
\text { Diverse nanostructures can be fab- } \\
\text { ricated }\end{array}$ & $\begin{array}{l}\text { High cost } \\
\text { Viscosity of the solution needs to be } \\
\text { maintained } \\
\text { Rheology of the material is crucial }\end{array}$ & Polymeric and composite aerogels \\
\hline
\end{tabular}

However, the assembly of lower-dimensional nanostructures or the building blocks is difficult to control and that can be achieved by adding templates in order to get a more ordered arrangement.

\section{Emulsion method}

Alnaief et al. established an emulsion-based method. This method is advantageous for synthesizing aerogels in microspherical form by maintaining the internal structural properties identical to that of monolithic aerogels [24]. This method involves the preparation of dispersed phase by sol-gel process and emulsification in a continuous phase followed by crosslinking reaction within the dispersed phase to form stable microspheres. The oil-water emulsion functions as the cross-linking medium. They synthesized the microspherical particles of both inorganic $\left(\mathrm{SiO}_{2}\right)$ and polymeric aerogels (Starch, Alginate) by this method [25, 26]. The aerogel in the form of microspheres or granules is also equally important for energy conversion and drug delivery applications. But, it is very difficult to obtain microspherical particles simply by grinding or milling the monolithic form generally obtained through the sol-gel method.

\section{3-D printing}

Three dimensional (3-D) printing is a hybrid modern technology evolved for the fabrication extremely lightweight $3-\mathrm{D}$ porous nanostructures by combining 3-D printing and nanotechnology [27]. 3-D Printing is a process of fabricating 3-D structures by assembling the building blocks layer by layer based on the virtual model of the structure [28]. This method is beneficial for the fabrication of composite and polymeric aerogels [29]. For example, nickel cobalt sulphide/grapheme composite aerogels were prepared by 3-D printing technology [30]. Cellulose nanocrystal based aerogels with a dual pore structure were obtained by a 3-D printing technique [31]. Moreover, aerogels were fabricated with diverse nanostructures such as octet cube, pyramid and honeycomb type demonstrate the flexibility of 3-D printing technology [32].

\section{Mechanism of network formation}

As it is described earlier, the formation of the aerogel network involves two fundamental steps namely hydrolysis of the precursor and condensation of primary nanoparticles. The formation of the network depends on these two fundamental steps. In the first step, the alkoxide precursor undergoes nucleophilic substitution by hydroxyl groups during hydrolysis. In the second step, the cross-linking reactions occur between $\mathrm{M}-\mathrm{OH}$ groups with the elimination of water or between $\mathrm{M}-\mathrm{OH}$ and $\mathrm{M}-\mathrm{OR}$ groups with the elimination of alcohol during condensation $[17,33]$. The cross-linking reactions and the internal structural changes continue to occur until the development of a mechanically stable network structure. The general mechanism involved in aerogel network formation may be represented as follows. 
Fig. 3 Schematic diagram of aerogel synthesis by sol-gel method. Reproduced with permission from [17]

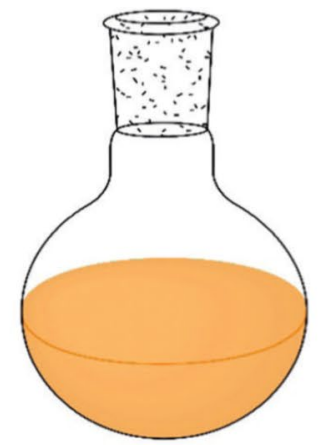

Solution of precursor
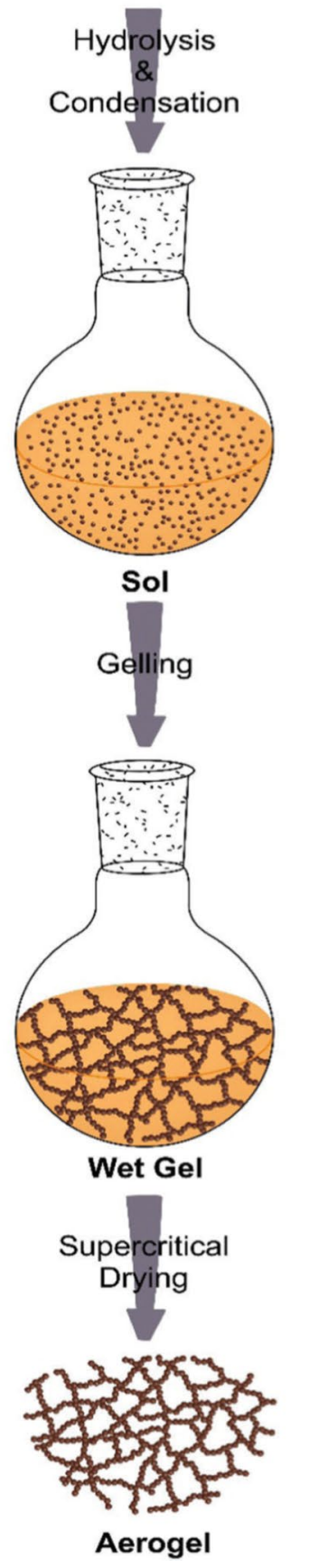

$\mathrm{M}-\mathrm{OR}+\mathrm{R}-\mathrm{OH}$ or $\mathrm{H}_{2} \mathrm{O} \rightarrow \mathrm{M}-\mathrm{OH}+\mathrm{R}-\mathrm{OH}$ (Hydrolysis)

$\mathrm{M}-\mathrm{OH}+\mathrm{HO}-\mathrm{M} \rightarrow \mathrm{M}-\mathrm{O}-\mathrm{M}+\mathrm{H}_{2} \mathrm{O}$ (Condensation of two $\mathrm{M}-\mathrm{OH}$ groups )

$\mathrm{M}-\mathrm{OR}+\mathrm{HO}-\mathrm{M} \rightarrow \mathrm{M}-\mathrm{O}-\mathrm{M}+\mathrm{R}-\mathrm{OH}$ (Condensation

$\mathrm{M}-\mathrm{OH}$ and $\mathrm{M}-\mathrm{OR}$ groups)

In sol-gel method, the rate of hydrolysis and the condensation are very fast and difficult to control which affects the final properties of the network. Therefore, epoxides were used to initiate the gelation which is getting protonated in the first step and undergoes ring opening in the second step. The $\mathrm{pH}$ of the solution slowly increases and starts the condensation and the rate of condensation slow which is beneficial for tailoring the properties of aerogel network. However, the aerogels prepared by the sol-gel method are amorphous and require further calcination leads to loss of many unique properties of aerogels.

Schaefer and Keefer proposed two kinetic models for the growth of the gel network based on used Small Angle X-ray Scattering (SAXS) study [34, 35]. Under acidic conditions, hydrolysis is favoured and the condensation becomes the rate-determining step. A large number of primary particles or small clusters are simultaneously formed and condensed together to form an interconnected network structure with smaller pores. This process is called reaction limited cluster aggregation (RLCA). Under basic conditions, hydrolysis becomes slow and the condensation of primary particles occurs very fast. Therefore, the primary particles formed during hydrolysis are immediately condensed together and the cluster grows by the condensation of primary particles. This process is called reaction limited monomer cluster (RLMC) growth or Eden growth. According to this process, the condensation of two clusters with each other is unfavourable.

Brinker et al. also developed a two-step method in which the alkoxide precursor undergoes hydrolysis first and forms reactive clusters followed by the condensation of the clusters, initiated by the addition of aqueous acid or base. They concluded that the reactive clusters formed in the first step are responsible for the formation of a network and independent of the catalyst used in the second step [36].

Boal et al. proposed a brick and mortar strategy for the self assembly of nanoparticles into secondary structured assemblies [21]. In this strategy, the functionalized colloidal nanoparticles act as bricks and a polymer acts as mortar. The networks were formed by assembling $97 \pm 17 \mathrm{~nm}$ sized spherical aggregates, which was formed through $2 \mathrm{~nm}$ size nanoparticle building blocks [21].

Recently, Lu et al. explained two strategies for the formation of secondary nanoparticle structures from their building blocks with and without templates as shown in Fig. 4 [37]. These strategies are analogous to the models proposed for the aerogel network formation earlier. 


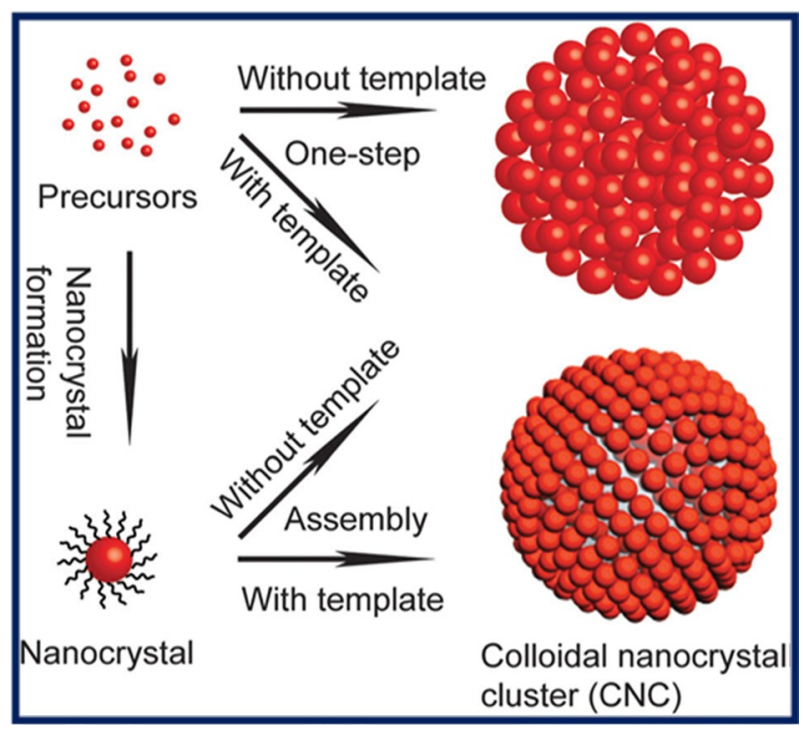

Fig. 4 Synthetic strategies for colloidal nanoparticle clusters Reproduced with permission from [37]

(i) One-step process which integrates the synthesis of nanoparticle and their aggregation into a cluster

(ii) Multi-step processes in which the nanoparticles with the desired size, shape and surface functionality are formed first and then assemble them into clusters of intended structures in various steps through electrostatic attraction.

The single-step method is more suitable to synthesize nanostructures and the nanoparticles obtained through this method have narrow size distributions result in more uniform structures. However, controlling the aggregation of nanoparticles during synthesis is very complicated. But, the multi-step method provides the number of possibilities to organize the primary nanoparticles and results nanostructures with tailored properties [37]. The nanoparticle clusters may be obtained through a number of ways such as thermolysis, solvothermal and microwave methods. In thermolysis method, the interparticle agglomeration is initially controlled by the steric effects of organic capping ligands to form uniform nanoparticles. Then, the condensation of primary nanoparticles to form 3-D nanostructures is initiated by increasing the temperature and by decreasing the degree of ligand protection. Maintaining the appropriate concentration of capping ligands is crucial not only for protecting the primary nanoparticles but also to stabilize the 3-D nanostructures. The microwave irradiation eradicates the problems of inhomogeneous heating and slow reaction kinetics of thermolysis method. However, the evaporation induced self assembly (EISA) is considered to be a powerful method to obtain high surface area and fully crystalline networks $[38,39]$.
Because this method is having control over the crystallinity of the final nanostructure as it employs crystalline nanoparticles as building blocks. Therefore, it is very difficult to distinguish the formation of the aerogel network and the colloidal nanoparticle clusters. It may be implicit that the primary nanoparticles (building blocks) undergo physical condensation results in nanoparticle clusters and the chemical crosslinking of primary nanoparticles (building blocks) formed immediately after hydrolysis resulting in the formation of aerogel network structure.

\section{Drying techniques}

The drying techniques are also equally important in aerogel synthesis as network formation. The three-dimensional gel network formed by condensation of primary particles needs to be preserved without any shrinkage after drying the gel. When the gel network is formed by hydrolysis and condensation, the pores are occupied by the solvents used for synthesis. Now, it is very crucial to remove the pore liquid without shrinking the gel network due to the formation of liquid-vapour meniscus, which recedes the pore walls.

The capillary pressure acting on the pore walls is inversely proportional to the pore radius which is controlled by the surface tension of the liquid.

$P_{\mathrm{c}}=\frac{2 \gamma \cos \theta}{r_{\mathrm{p}}}$

Here, $P_{\mathrm{c}}$ is capillary pressure, $\gamma$ is the surface tension of the pore liquid and $r_{\mathrm{p}}$ is pore radius which is represented by $r_{\mathrm{p}}=\frac{2 V_{\mathrm{p}}}{S_{\mathrm{p}}}$

Here, $V_{\mathrm{p}}$ is pore volume and $S_{\mathrm{p}}$ is surface area.

The pore liquid flows out to the surface from the interior of the gel network during drying causes deformation of the gel network or shrinkage in volume. The shrinkage of the gel network brings the surface hydroxyl groups very closer and makes them react with each other. The conventional drying techniques like simple heating or drying at room temperature leads to shrinkage of the gel network and the rough surfaces will be collapsed upon drying due to these capillary forces acting on pore walls. Therefore, if the gel is dried by conventional drying, the microporous xerogels are obtained. On the other hand, some special drying techniques such as supercritical drying, freeze drying and subcritical drying were adopted to preserve the 3-D network structure by minimizing the capillary forces acting on the pore walls. These methods diminish the capillary forces and avoid the shrinkage of the pore structure leads to the formation of mesoporous aerogels [40]. 


\section{Supercritical drying}

The capillary forces developed by the surface tension of the pore liquid are responsible for shrinkage of porous network structure. To minimize the capillary force, it is necessary to reduce the surface tension of the pore liquid. One convenient way of accomplishing this is converting the pore liquid into the fluid which is having zero surface tension. The capillary force acting on the pore wall becomes zero since the surface tension of the liquid is directly proportional to capillary forces. This is the principle behind the supercritical drying method [40, 41]. Therefore, the removal of pore liquid under supercritical condition preserves the porous network structure of the wet gel without experiencing considerable shrinkage. However, the supercritical drying involves high temperature and pressure depending upon the pore liquid. The high temperature and pressure create safety problems in this method. Also, the rearrangement reactions in the gel network are possible under these conditions which cause a reduction in surface area. Therefore, low-temperature supercritical drying with liquid carbon dioxide was introduced to overcome these problems. The critical point of liquid carbon dioxide is relatively low compared to the other solvents. The structural changes are very minor in this case and the porous network formed in the wet gel state can be preserved [42-44]. However, the exchange of pore liquid with liquid carbon dioxide is time consuming process and the miscibility problem still extends the time by intermediate solvent exchange.

\section{Freeze drying}

Another drying technique used to preserve the porous network is called freeze drying. In this method, the pore liquid is first taken to its freezing point and the frozen solid is removed by sublimation under vacuum without affecting the pore walls. The porous material obtained in this method is called cryogels and their surface area, pore volume will be slightly smaller than aerogels. The pore liquid should be exchanged with another liquid of low expansion coefficient and freezing point in the same way as supercritical drying. However, the pore liquid crystallizes inside the pores which collapse the 3-D network structure.

\section{Ambient pressure drying}

The supercritical drying and freeze-drying techniques are not viable processes for commercial production of aerogels due to risk and high cost involved in these processes. However, ambient pressure drying is very simple and economically viable for large scale production of aerogels [45]. Therefore, different approaches were implemented to remove pore liquid under ambient conditions without shrinkage in the network. To minimize the capillary forces exerted on the pore walls the contact angle between the pore liquid and the pore walls is altered by adding surfactants.

The surface hydroxyl groups of the inner and outer surface of the network structure were modified with bulky groups such as chlorotrimethylsilane or hexamethyldisiloxane $[46,47]$. Therefore, the surface of the gel network becomes highly hydrophobic and the reactivity is very low. Then the gel network is subjected to conventional drying. The gel network undergoes shrinkage when the pore liquid is evaporated. However, the cross-linking reactions ( $\mathrm{Si}-\mathrm{O}-\mathrm{Si}$, $\mathrm{Ti}-\mathrm{O}-\mathrm{Ti}$ ) between the surface hydroxyl groups are prevented by the bulky groups and the shrinkage becomes reversible. Therefore, the network expands back to its original size and this phenomenon is called spring back effect.

Besides, a very simple solvent exchange method was employed to get aerogel nanostructure under ambient conditions. In this technique, the pore liquid was effectively exchanged with another liquid having low surface tension without affecting the walls of the pores present in the aerogel network. They concluded that a solvent with low surface tension, low vapour pressure and high molecular volume favours the production of high surface area aerogels [48].

\section{Organic solvent sublimation drying}

Recently, Ren et al. developed another method called organic solvent sublimation method (OSSD), solvents such as acetonitrile and tert-butanol with low surface tension, high freezing point and undergo sublimation easily could be removed simply by sublimation under vacuum [49]. In this method, the $\mathrm{M}-\mathrm{O}-\mathrm{M}$ bridges formed through the surface hydroxyl groups preserve the network structure in a certain elastic range. As the drying proceeds by increasing vacuum, the organic solvent present at the outer surface evaporates first and that leads to the instant reduction in the internal temperature of the gel which results in a portion of the solid becomes solid. This solidified solvent undergoes sublimation which further lead to more solvent becomes solid. This process continuously occurs and avoids the influence of surface tension and solvent crystallization inside the pores. The mechanism of this method is schematically represented in the Fig. 5. The method was successfully implemented to synthesize oxide aerogels like $\mathrm{SiO}_{2}, \mathrm{Al}_{2} \mathrm{O}_{3}, \mathrm{Fe}_{2} \mathrm{O}_{3}, \mathrm{NiO}$. The oxide aerogels were remained intact and crack-free irrespective of whether $t$-butanol or acetonitrile was used as solvent. The complete removal of solvents from the network by sublimation during the drying process was confirmed by FT-IR analysis. It was concluded that the OSSD drying process is extremely simple, convenient and time-saving method for large scale synthesis of aerogels without the need for any high temperature and pressure instruments. 


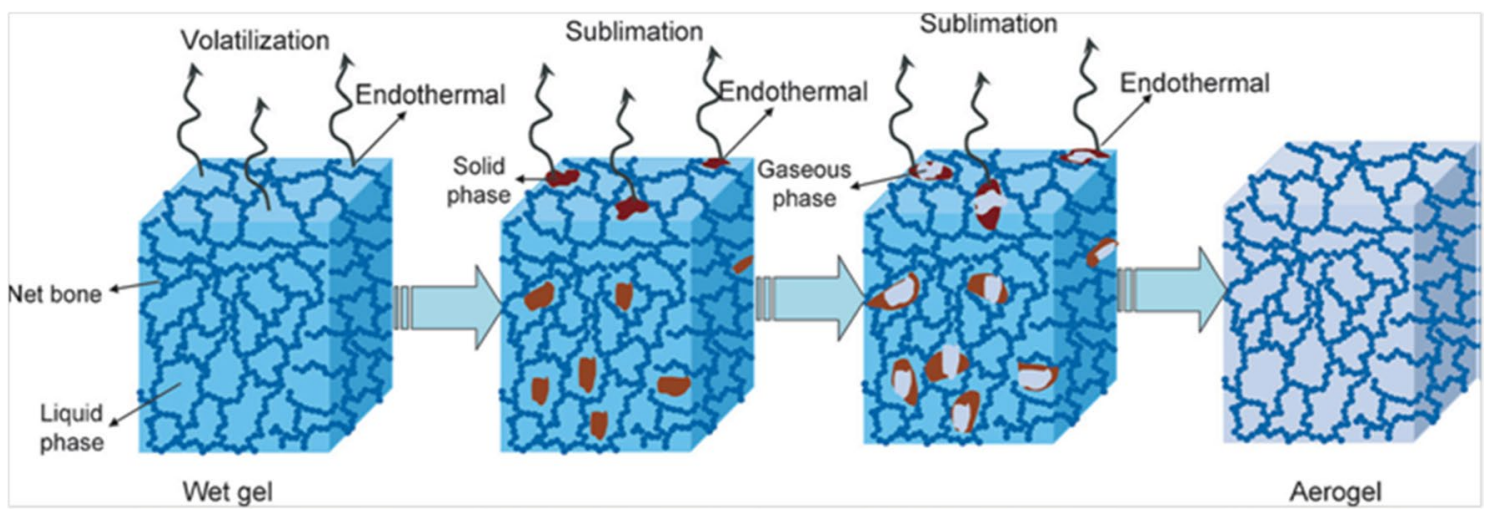

Fig. 5 Mechanism of organic solvent sublimation drying technique Reproduced with permission from [49]

\section{Application of inorganic aerogels}

The history of aerogel had commenced with the synthesis of inorganic aerogel, particularly with silica aerogel. The inorganic aerogels are generally made up of $\mathrm{M}-\mathrm{O}-\mathrm{M}, \mathrm{M}-\mathrm{M}$ or $\mathrm{M}-\mathrm{S} / \mathrm{Se}$ basic functional units derived from the precursors such as metallic salts or metallic alkoxides. Inorganic aerogels are widely employed as electrode materials in dyesensitized solar cells, batteries and catalyst support in fuel cells owing to its high specific surface area, open porous structure and semiconducting properties.

\section{Oxide aerogels}

In 1931, Kistler first synthesized $\mathrm{SiO}_{2}$ aerogels from an aqueous solution of sodium silicate and hydrochloride. $\mathrm{He}$ demonstrated that the liquid present in the gel network can be removed without destroying the gel structure by employing supercritical drying [50]. Initially, $\mathrm{SiO}_{2}$ aerogels were used as thermal insulators, particle detectors and for cosmic dust collectors. The recent applications of inorganic aerogels in energy conversion storage devices are presented in Table $2 . \mathrm{SiO}_{2}$ aerogels were employed as catalyst support for polymer electrolyte membrane fuel cells [51]. $\mathrm{SiO}_{2}$ aerogel prevents the Pt nanoparticle aggregation and effective transfer of fuel oxidant and products. However, the higher concentration of $\mathrm{SiO}_{2}$ aerogel results in mass transport losses at high current density values and affects the electron transfer pathway. Silica aerogel supported Pt nanoparticle was synthesized through microwave-assisted method and used as filler in Nafion recast membranes. The presence of $\mathrm{SiO}_{2}$ aerogel improved the water uptake and provides self humidification even under elevated temperatures which was

Table 2 Different applications of inorganic aerogels in energy conversion and storage devices

\begin{tabular}{|c|c|c|c|c|c|}
\hline S.No & Aerogel & Drying technique & $\begin{array}{l}\text { Surface area } \\
\left(\mathrm{m}^{2} / \mathrm{g}\right)\end{array}$ & Application & References \\
\hline 1 & $\mathrm{SiO}_{2}$ & Freeze drying & 594 & Self humidifying PEMs in fuel cell & {$[52]$} \\
\hline 2 & $\mathrm{TiO}_{2}$ & Supercritical drying & 144 & Photoanode in DSSCs & {$[55]$} \\
\hline 3 & $\mathrm{TiO}_{2}$ & Supercritical drying & 112 & Photoanode in DSSCs & {$[56]$} \\
\hline 4 & Plasma treated $\mathrm{TiO}_{2}$ & Solvent exchange & 273 & Photoanode in DSSCs & {$[58,59]$} \\
\hline 5 & $\mathrm{TiO}_{2}$ & Solvent exchange & 299 & Photoanode in DSSCs & {$[60]$} \\
\hline 6 & $\mathrm{CoO}_{2}$ & Supercritical drying & 235 & Electrodes for supercapacitor & {$[64]$} \\
\hline 7 & $\mathrm{~V}_{2} \mathrm{O}_{5}$ & Supercritical drying & 80 & Anode material for Na-ion/Li-ion battery & {$[65,66]$} \\
\hline 8 & $\mathrm{LiTiO}_{3}$ & Supercritical drying & 50 & Anode material for Li-ion battery & {$[67]$} \\
\hline 9 & Metallic aerogels ( $\mathrm{Au}, \mathrm{Pd})$ & Supercritical drying & 56 & Electro oxidation of ethanol in fuel cell & {$[76,77]$} \\
\hline 10 & $\mathrm{Pt}_{3} \mathrm{Ni}$ & Supercritical drying & - & Anode electrocatalyst in fuel cell & {$[80,81]$} \\
\hline 11 & $\mathrm{Pd}-\mathrm{Cu}$ & Supercritical drying & 37.5 & Electrocatalyst for fuel cell & {$[82]$} \\
\hline 12 & $\mathrm{SiO}_{2} / \mathrm{TiO}_{2}$ hybrid & Ambient pressure drying & 650 & Photoanode in DSSCs & [128] \\
\hline 13 & $\mathrm{ZnO} / \mathrm{TiO}_{2}$ bilayer & Solvent exchange & 7.5 & Photoanode in DSSCs & {$[130]$} \\
\hline 14 & $\mathrm{Sb}$ doped $\mathrm{SnO}_{2}$ & Supercritical drying & & Counter electrode in DSSC & [133] \\
\hline 15 & Pt doped $\mathrm{TiO}_{2}$ & Supercritical drying & 162 & Photocatalyst for hydrogen production & [138] \\
\hline
\end{tabular}


enhanced the power density 5.5 times compared to pristine Nafion recast membranes [52].

$\mathrm{TiO}_{2}$ aerogel is an important metal oxide aerogel studied subsequent to silica aerogels [53]. $\mathrm{TiO}_{2}$ aerogel finds applications in dye-sensitized solar cells as photoanode material due to its high surface area and wide bandgap. DSSC employs a thin semiconductor nanoparticle layer with a monolayer of dye molecules as photoanode. The DSSC performance depends upon photon absorption which in turn varies with the amount of dye adsorption [54]. Therefore, the amount of dye adsorbed on the semiconductor layer governs the photon absorption, accordingly the specific surface area and the surface chemistry of semiconductor material which is used as photoanode in DSSC plays a significant role in increasing the amount of dye adsorption. Baia et al. first proposed $\mathrm{TiO}_{2}$ aerogel for photovoltaic applications [55], whereas Rolison et al. first used $\mathrm{TiO}_{2}$ aerogels as photoanode material in dye-sensitized solar cells [56]. They have concluded that $\mathrm{TiO}_{2}$ aerogel photoanode performs well in longer wavelengths due to better light scattering properties. Chiang et al. reported the superior properties of $\mathrm{TiO}_{2}$ aerogel photoanode over P25 photoanode in DSSCs. The short-circuit current density was high in aerogel based DSSCs, mainly due to increased dye loading because of high surface area. Also, they achieved a better power conversion efficiency of 8.36\% for $\mathrm{TiO}_{2}$ aerogel photoanode based DSSC compared to P25 photoanode based DSSC (7.22\%). The improvement in efficiency was attributed to the high surface area, large pores, high porosity and 3-D interconnected structure of the aerogel nanostructure [57].

The results of the recent study on $\mathrm{TiO}_{2}$ aerogels as photoanode material for DSSCs are very interesting. $\mathrm{TiO}_{2}$ aerogels were synthesized through sol-gel method followed by ambient pressure drying technique. Then, the aerogel layer was subjected to low pressure $\left(1.5 \times 10^{-2}\right.$ mbar) oxygen plasma treatment [58]. The FESEM images of plasma treated and untreated $\mathrm{TiO}_{2}$ aerogels are shown in Fig. 6. It is observed that the continuous solid network structure is retained after plasma treatment. The specific surface area is increased from 252 to $273 \mathrm{~m}^{2} / \mathrm{g}$ and inserted additional hydrophilic groups on the aerogel surface. Plasma treated $\mathrm{TiO}_{2}$ aerogels were employed as photoanode material in quasi-solid DSSCs. The schematic representation of the DSSCs fabricated using aerogel photoanode is shown in Fig. 7a. The DSSC fabricated using $\mathrm{TiO}_{2}$ aerogel with 10 min of oxygen plasma treatment as photoanode yields a power conversion efficiency of 3.94\% along with a short-circuit current density of $9.45 \mathrm{~mA} /$ $\mathrm{cm}^{2}$ and an open-circuit voltage of $0.694 \mathrm{~V}$ which is significantly higher than that of the DSSC fabricated using untreated $\mathrm{TiO}_{2}$ aerogel as photoanode $(3.08 \%, 8.64 \mathrm{~mA} /$ $\mathrm{cm}^{2}, 0.66 \mathrm{~V}$ ) (Fig. 7b). This improvement in efficiency is mainly due to the enhanced amount of dye adsorption by means of increased specific surface area and the insertion of additional hydrophilic groups achieved through plasma treatment [59]. This work involves the modification of the surface of already synthesized aerogel powder whereas the other interesting report explains the synthesis of high surface area aerogel by controlling the size of the primary nanoparticle building blocks through microwave irradiation. $\mathrm{TiO}_{2}$ aerogels were obtained by microwave-assisted method for DSSC applications. The microwave irradiation prevailed inter-particle interactions and retards the formation of larger particles, increased the specific surface area to $299 \mathrm{~m}^{2} / \mathrm{g}$. A maximum power conversion efficiency of $5.2 \%$ with a short-circuit current density of $15.18 \mathrm{~mA} /$ $\mathrm{cm}^{2}$ and an open-circuit voltage of $0.62 \mathrm{~V}$ was realized in quasi-solid DSSCs by using this high surface area $\mathrm{TiO}_{2}$ aerogel as photoanode material (Fig. 7c). The substantial increase in power conversion efficiency is mainly due to the increase in short-circuit current, which is accomplished by a large amount of dye adsorption achieved through high surface area $\mathrm{TiO}_{2}$ aerogel [60].

Mesoporous metal oxides with high surface area and porosity are excellent candidates for supercapacitor applications because the specific capacitance of an electrode depends on the specific surface area and pore size distribution [61, 62]. In addition, they possess pseudo capacitances along with electric double-layer capacitance [63]. Wei et al. successfully synthesized $\mathrm{CoO}_{2}$ aerogel with an epoxide addition method and used as an electrode in supercapacitor. The specific capacitance of $623 \mathrm{~F} / \mathrm{g}$ was achieved even with a loading of $1 \mathrm{mg} / \mathrm{cm}^{2}$ and a scan rate $25 \mathrm{mV} / \mathrm{s}$, which is much higher than that of the other $\mathrm{CoO}_{2}$ nanostructures [64]. Moretti et al. synthesized layered $\mathrm{V}_{2} \mathrm{O}_{5}$ aerogel and used as an intercalation host for $\mathrm{Na}^{+}$ions for the application of sodium battery anode. $\mathrm{V}_{2} \mathrm{O}_{5}$ aerogel anode delivers a capacity of $200 \mathrm{mAh} / \mathrm{g}$ in the voltage range $0.01-1.5 \mathrm{~V}$. Also, the $\mathrm{Na}^{+}$cell prepared using this anode and $\mathrm{Na}_{3} \mathrm{~V}_{2}\left(\mathrm{PO}_{4}\right)_{3}$ as cathode showed a voltage of $2.5 \mathrm{~V}$ with a maximum specific capacity of $113 \mathrm{mAhg}^{-1}$ of anode material [65]. When it was used in Li-ion batteries as anode, a discharge capacity of $300 \mathrm{mAh} / \mathrm{g}$ was obtained which corresponds to the insertion of 2.2 equivalents of lithium per mole of $\mathrm{V}_{2} \mathrm{O}_{5}$. However, at $1 \mathrm{C}$ rate the materials showed a reversible capacity of $130 \mathrm{mAh} / \mathrm{g}$ indicating that there was no structural damage occurred [66]. The average cell voltage of $2.5 \mathrm{~V}$ is obtained which is higher than that of nickel metal hydride and vanadium redox flow batteries. The large interlayer spacing between the $\mathrm{V}_{2} \mathrm{O}_{5}$ layers facilitates the electrolyte penetration and $\mathrm{Na}$ or $\mathrm{Li}$ ion insertion-deinsertion properties. Another interesting work explains the use of lithium titanate aerogel as an anode material for Li-ion battery. A specific capacity of $137 \mathrm{mAh} / \mathrm{g}$ was achieved which is comparable to commercial lithium titanate anode material [67].

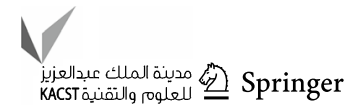


Fig. 6 FESEM images of $\mathrm{TiO}_{2}$ aerogel powder as synthesized (a), aerogel layer (b), before and after plasma treatment (c, d low magnification), (e, $\mathbf{f}$ high magnification). Reproduced with permission from [58]

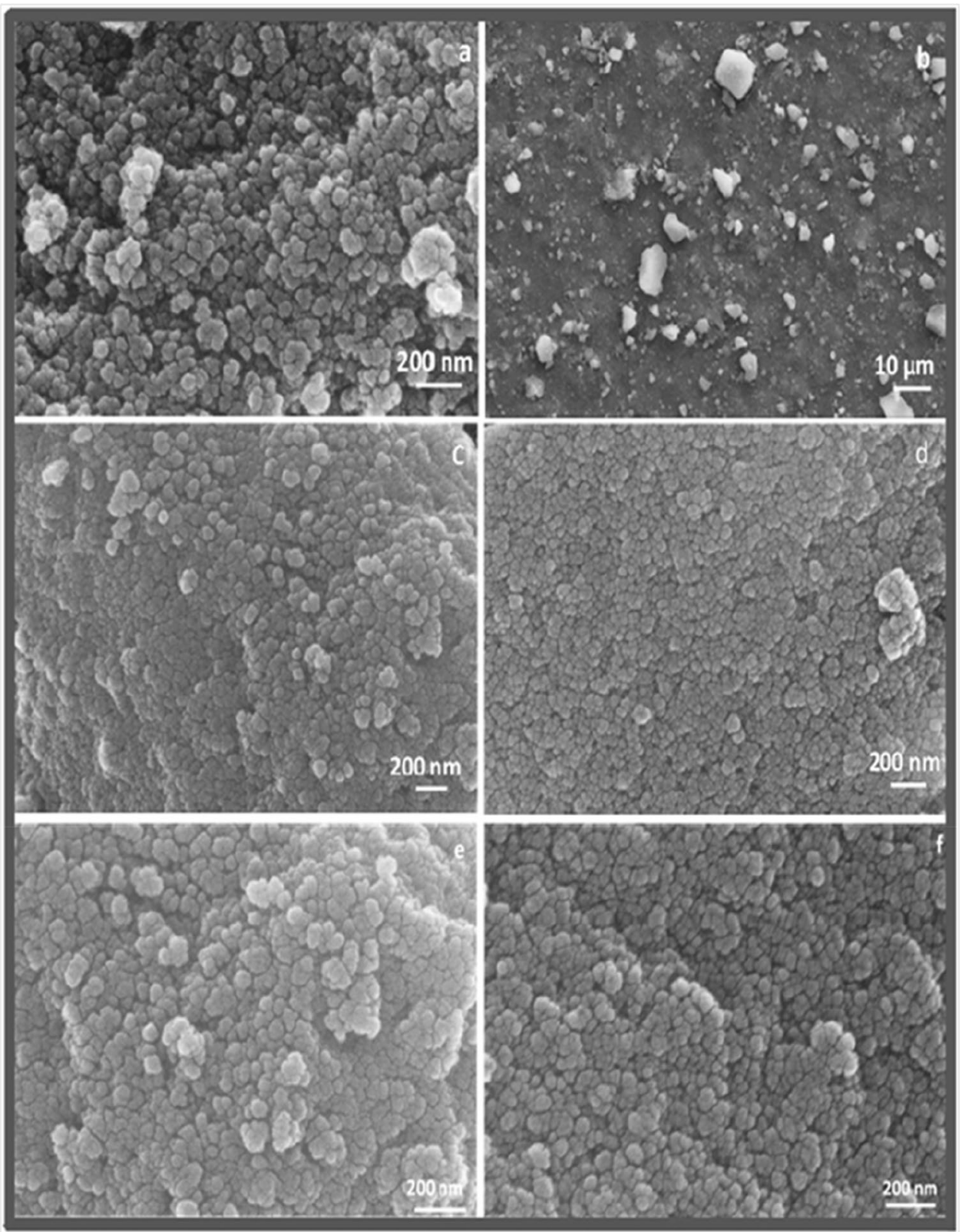

\section{Chalcogenide and metallic aerogels}

Brock et al. prepared chalcogenide aerogels such as $\mathrm{CdSe}$, $\mathrm{CdS}, \mathrm{ZnS}$ through the oxidative aggregation of chalcogenide nanoparticle building blocks followed by supercritical drying. These aerogels exhibit a specific surface area in the range between 120 and $250 \mathrm{~m}^{2} / \mathrm{g}$, which is comparable to other oxide aerogels. It is anticipated that these aerogels could be effectively employed for photovoltaic applications $[68,69]$.

Other than metal oxide and chalcogenide aerogel nanostructures, recently metallic aerogels were reported by Leventis and his group. They have developed $\mathrm{Fe}, \mathrm{Co}, \mathrm{Ni}, \mathrm{Cu}$ and Sn aerogels by a carbothermal method [70, 71]. Eychmuller et al. synthesized noble multimetallic aerogel networks by template free self-assembly process [72-74]. The network structure of multimetallic aerogels is shown in Fig. 8. Pd aerogels were prepared by reducing $\mathrm{K}_{2} \mathrm{PdCl}_{4}$ with $\mathrm{NaBH}_{4}$ in the presence of cyclodextrin yields Pd aerogel. These aerogels exhibit very high activities towards electrooxidation of ethanol [75, 76]. Gold aerogels were prepared by dopamine-induced process in which the Au nanoparticles undergo gelation without preaggregation. It was reported that the aerogel composed of nanowire like networks made up of 5-6 nm sized Au nanoparticles. These aerogels have shown very high activities toward the oxidation of glucose due to fast electron transfer kinetics, open porous structure and high surface area of gold aerogel. In addition, it shows 
Fig. 7 a Schematic representation of aerogel based DSSCs, Photocurrent-Voltage characteristics of DSSCs (b) prepared with untreated and plasma treated $\mathrm{TiO}_{2}$ aerogels, c prepared using $\mathrm{TiO}_{2}$ aerogels synthesized through microwave assisted sol-gel method Reproduced with permission from $[59,60]$

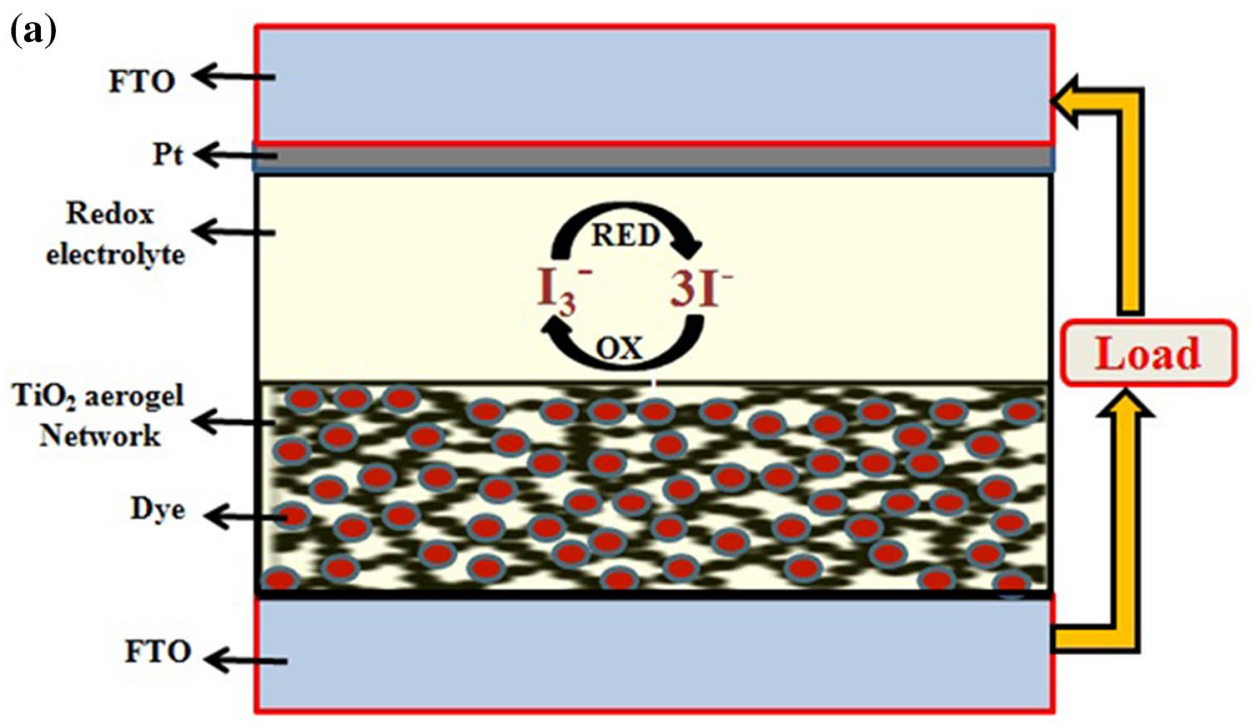

(b)

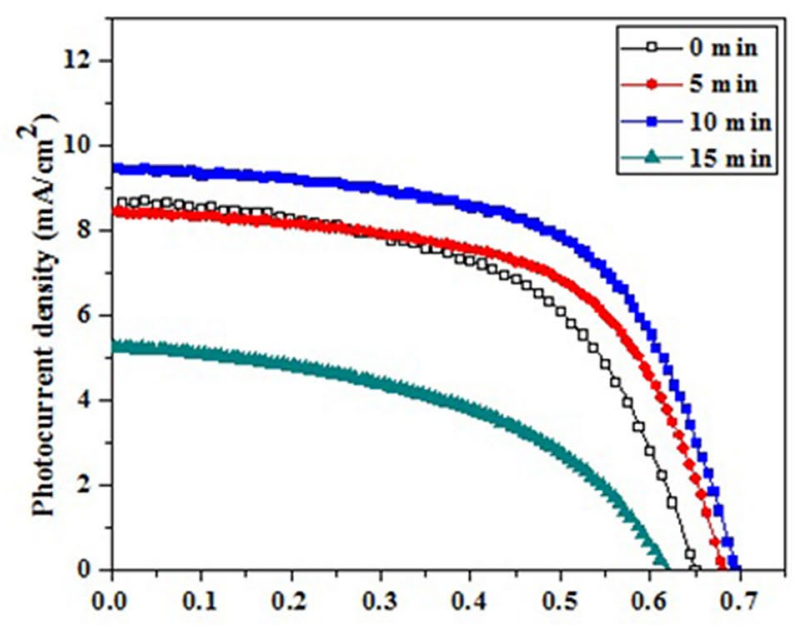

(c)

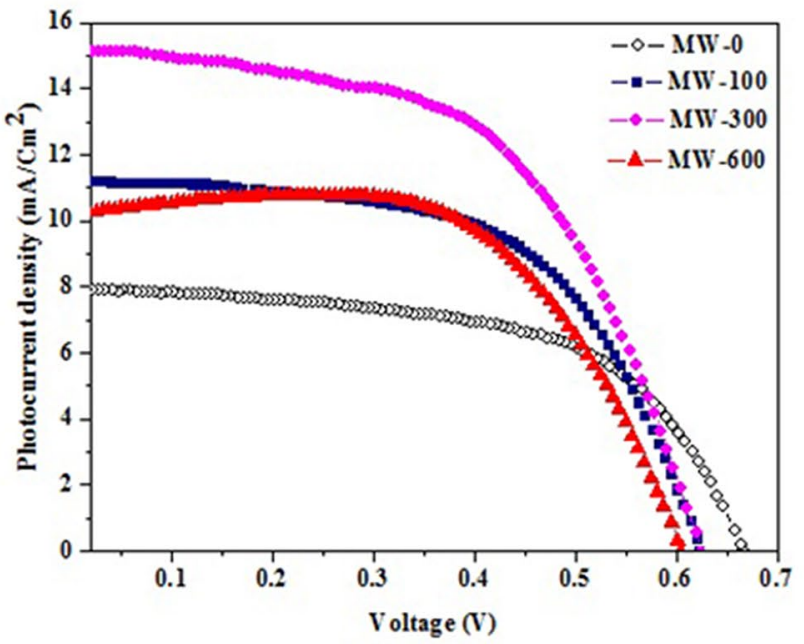

the highest catalytic activity towards ethanol oxidation indication the potential use of gold aerogel as fuel cell catalyst [77].
For automotive application, PEFC electrodes should work under stringent conditions such as continuous start up/shut down cycles and fuel starvation. In such cases, the electrodes 
Fig. 8 TEM images showing 3-D network structure of multimetallic aerogels Reproduced with permission from [74]
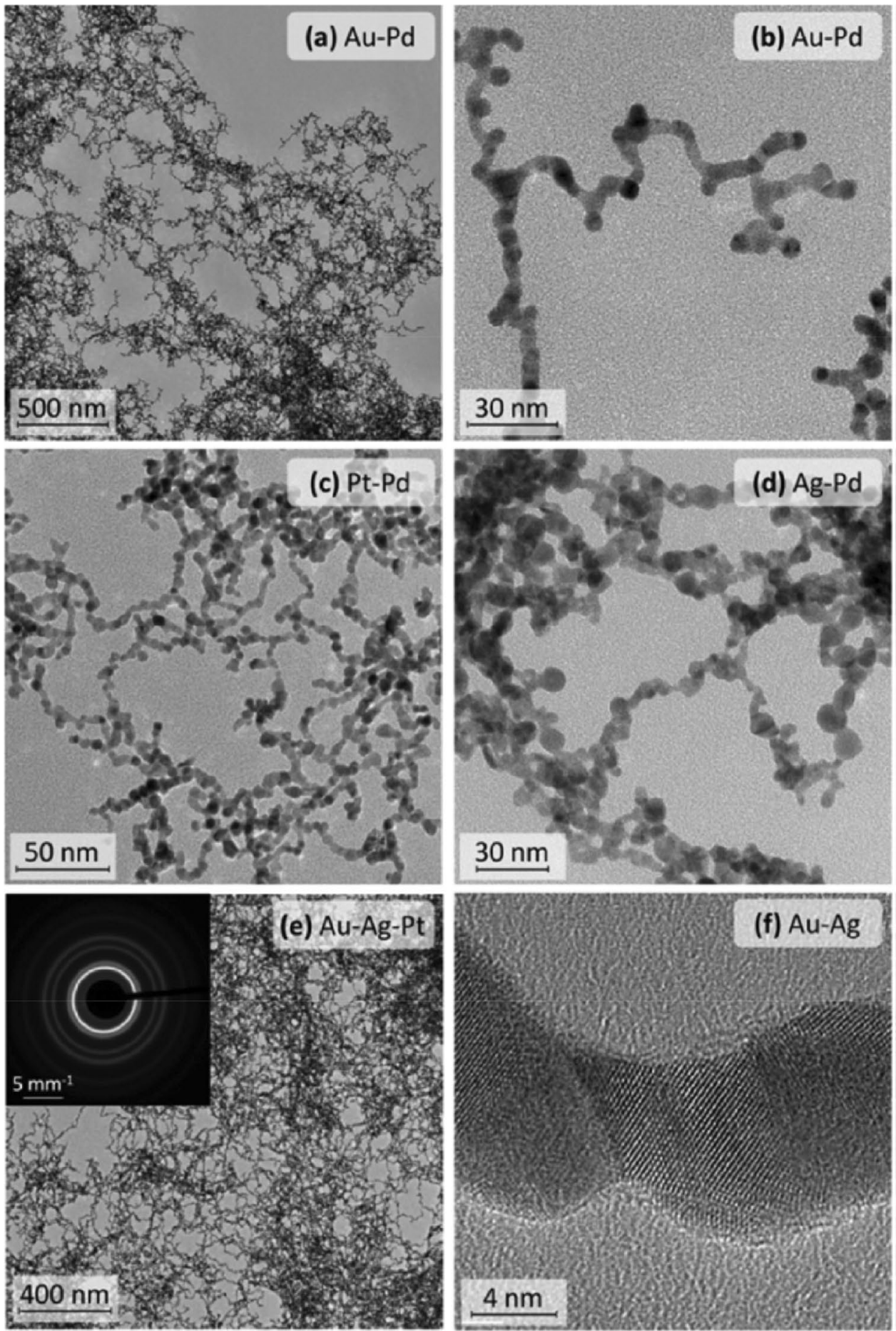

undergo corrosion which limits the durability of the electrodes and fuel cell stack life. Therefore, a robust electrocatalyst is essential for the commercial success of polymer electrolyte fuel cells [78]. The introduction of non-noble metal into bimetallic catalysts significantly reduces the cost of fuel cells and corrosion of the support materials at high current density operation [79]. The alloying of Pt with Ni not only reduce the cost but also down shift the d-band center which decreases the fractional coverage of spectator species at a given potential and increases the number of free sites for oxygen adsorption and high oxygen reduction activity. Pt-Ni bimetallic aerogels were synthesized and found that the activity of oxygen reduction reaction improved three times compared to commercial platinized carbon electrocatalyst [79]. In pristine Pt electrocatalyst the $d$ band center is too close to the fermi level and the rate of oxygen reduction 
reactivity is decreased by the availability of $\mathrm{OH}^{-}$ion free sites. However, in the case of $\mathrm{Pt}_{3} \mathrm{Ni}$ catalyst, the d-band center is too far from the fermi level and the surface is less covered by the $\mathrm{OH}^{-}$species reducing the adsorption energy of $\mathrm{O}_{2}$ and the intermediates leading to high oxygen reduction activity [80]. Therefore, Henning et al. prepared an unsupported, bimetallic $\mathrm{Pt}_{3} \mathrm{Ni}$ aerogel and employed as anode catalyst for polymer electrolyte fuel cell (PEFC) application. The $\mathrm{Pt}_{3} \mathrm{Ni}$ electrocatalyst exhibits excellent durability and performance retention under stringent conditions and 35\% higher mass activity towards hydrogen oxidation reaction compared to commercial $\mathrm{Pt} / \mathrm{C}$ catalyst [81]. These results suggest that these metallic aerogel nanostructures are the sustainable electrocatalytic materials for fuel cell applications. $\mathrm{Pt}-\mathrm{Cu}, \mathrm{Pd}-\mathrm{Cu}$, and $\mathrm{Au}-\mathrm{Cu}$ bimetallic aerogels were also reported as electrocatalyst for ethanol oxidation in fuel cells [82].

\section{Application of organic aerogels}

Organic aerogels are generally characterized by the basic functional units of strong $\mathrm{C}-\mathrm{C}$ covalent bonds derived from the organic precursors. They are normally used as electrode materials in supercapacitors and fuel cells due to its high electronic conducting properties and electrocatalytic properties.

\section{Carbon aerogels}

Carbon aerogels are a unique class of materials that possess a tunable 3-D hierarchical morphology with high surface area and electrically conductive and chemically inert network structure. The recent progress in synthetic methodologies adopted for carbon aerogel and their applications to hydrogen storage, supercapacitor, battery, fuel cells and catalysis is reported [83]. Carbon aerogel was first prepared by Pekala et al. through sol-gel polymerization of resorcinal and formaldehyde in an aqueous medium. The sol-gel process yields a highly crosslinked polymeric gel, which was then supercritically dried. The pyrolysis of the polymeric network under inert atmosphere provides carbon aerogel [84]. Carbon aerogel was utilized as electrode material in electrochemical double-layer capacitor for the first time in Lawrence Livermore National Laboratory and an aerocapacitor was fabricated. A specific capacitance of $19.2 \mathrm{~F} / \mathrm{g}$ with a maximum power density of $1.2 \mathrm{~W} / \mathrm{cm}^{2}$ was achieved [85]. The specific capacitance values were improved from 20 to $82 \mathrm{~F} / \mathrm{g}$ by using Ru doped carbon aerogel as an electrode. It was concluded that the capacity improvement was not due to the high surface area, but because of Ru nanoparticles [86]. Probstle et al. fabricated a button cell supercapacitor using carbon aerogel and reported that the device shows excellent stability even after 80,000 charge-discharge cycles [87]. Zhu et al. used cresol instead of resorcinol, to reduce the cost of the material to synthesize carbon aerogel. They achieved a maximum specific capacitance of $146 \mathrm{~F} / \mathrm{g}$ at $1 \mathrm{~mA} / \mathrm{cm}^{2}$ and it was slightly decreased to $131 \mathrm{~F} / \mathrm{g}$ at $20 \mathrm{~mA} / \mathrm{cm}^{2}$ [88]. $\mathrm{Li}$ et al. varied resorcinol to catalyst ratio in the synthesis of carbon aerogel and found that $\mathrm{R} / \mathrm{C}=1500$ gives high specific capacitance [89]. Zapata et al. replaced resorcinol with lignin as a precursor and studied the effect of porosity and surface functionalities on the electrochemical capacitance of the activated carbon aerogels. They achieved a very high specific surface area of $1243 \mathrm{~m}^{2} / \mathrm{g}$ and a specific capacitance of $234.2 \mathrm{~F} / \mathrm{g}$ at a current density of $0.124 \mathrm{~A} / \mathrm{g}$ [90].

Flexible carbon aerogels were obtained by carbon dioxide supercritical drying of bacterial cellulose impregnated lignin-phenol formaldehyde hydrogel. The electrochemical performance of these electrodes shows a specific capacitance of $124 \mathrm{~F} / \mathrm{g}$ at a scan rate of $0.5 \mathrm{~A} / \mathrm{g}$. The unique blackberry like structure and large mesopore concentration with good interpore connectivity of these materials facilitate ion transportation and lead to high capacitance [91]. In another study, the lignin-based carbon aerogels exhibit a specific surface area of $799 \mathrm{~m}^{2} / \mathrm{g}$ and a specific capacitance of $142.8 \mathrm{~F} / \mathrm{g}$ at a current density of $0.5 \mathrm{~A} / \mathrm{g}$. The specific capacitance of these electrode remains $112.5 \mathrm{~F} / \mathrm{g}$, even at a large current density of $10 \mathrm{~A} / \mathrm{g}$ [92].

Carbon aerogel was also used as catalyst support for polymer electrolyte membrane fuel cells. Smirnova et al. employed carbon aerogels as catalyst support for fuel cell applications [93]. It was reported that an increase in average pore size from 16 to $20 \mathrm{~nm}$ results significant increase in cell performance and a maximum power density of 0.8 $\mathrm{mW} / \mathrm{cm}^{2}$ was achieved even with a low loading of the catalyst with $0.1 \mathrm{mg} / \mathrm{cm}^{2}$. This is due to the unique structure of aerogel support that provides better penetration of Nafion molecules into the larger pores and maintains good contact with the Pt particles available on the internal surface of the aerogel pores. However, the analysis of Tafel slope indicates that the cell performance at high current density is not as good as in low current density region due to mass transport losses. This is also supported by Marie et al. that the increase in pore size of carbon aerogel support increases the mass transport losses at the cathode. This is due to the penetration of Nafion into the larger pores lowers the effective porosity of catalyst support which hinders the mass transport [94]. Guilminot et al. synthesized Carbon aerogels by the pyrolysis of cellulose acetate and used as catalyst support for fuel cell catalysts. The specific surface area of the carbon aerogel is $450 \mathrm{~m}^{2} / \mathrm{g}$ and found that the mass activity of $\mathrm{Pt} /$ carbon aerogel was increased [95]. Mesoporous activated carbon aerogel with a specific surface area of $2161 \mathrm{~m}^{2} / \mathrm{g}$ was synthesized through template method. In this method, cetyl trimethylammonium

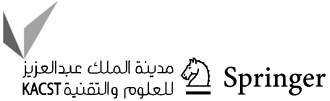


bromide was used as a template and $\mathrm{H}_{3} \mathrm{PO}_{4}$ was used as a porogen. The material was used as an electrode in lithium-ion battery and a maximum capacity of $610 \mathrm{mAh} / \mathrm{g}$ was achieved at a current density of $0.1 \mathrm{~A} / \mathrm{g}$ and it was decreased to $19 \mathrm{mAh} / \mathrm{g}$ at $5 \mathrm{~A} / \mathrm{g}$ [96]. Wang et al. synthesized a high surface area carbon aerogels with large open pores through pyrolysis of the natural resource bacterial nanocellulose. They have employed freeze-drying method to preserve the 3-D open network structure and used as an anode in lithium-ion batteries. The electrode delivers better capacity retention due to open pore structure and high surface area of carbon aerogels which offers a large electrode-electrolyte contact area favours charge transfer reaction [97]. Titanium and niobium carbide aerogels with the specific surface areas of 265 and $159 \mathrm{~m}^{2} / \mathrm{g}$ were prepared directly from carbon aerogels and used as counter electrodes in dye-sensitized solar cells. The studies suggest that the carbide aerogels showed excellent electrocatalytic activities towards $I^{-} / I_{3}^{-}$redox reaction [98].

\section{Carbon nanotube (CNT) aerogels}

Carbon nanotube aerogels are another exciting electrically conducting materials to find potential applications in battery and supercapacitor electrodes [99]. Bordjiba et al. grown carbon nanotubes directly on microfibrous carbon paper by chemical vapor deposition method. Then, the aquagel formed by dissolving polyacrylonitrile in a mixture of dimethylformamide and distilled water was coated. The pretreatment at $215^{\circ} \mathrm{C}$ for $20 \mathrm{~h}$ and carbonization at $850{ }^{\circ} \mathrm{C}$ for $8 \mathrm{~h}$ result CNT aerogel. The SEM image of the CNT aerogel grown on the substrate is shown in Fig. 9 and the cyclic voltammogram recorded at $20 \mathrm{mV} / \mathrm{s}$ is presented in Fig. 10. The curve exhibits an excellent capacitive behaviour observed by a rectangular shape expected for an ideal double-layer capacitor. The CNT aerogel electrode delivered an exceptionally high specific capacitance of $524 \mathrm{~F} / \mathrm{g}$ which demonstrates the great potential of CNT aerogel electrodes for supercapacitor applications [100]. Single walled carbon nanotube (SWCNT) aerogels were synthesized through the reductive coupling of SWCNTs and p-diiodobenzene in dimethylacetamide, followed by freeze drying of the organogels. A high specific surface area of $766 \mathrm{~m}^{2} / \mathrm{g}$ was obtained and used a supercapacitor electrode. The device delivered a specific capacitance of $55 \mathrm{~F} / \mathrm{g}$ at $1 \mathrm{~V} / \mathrm{s}$ with exceptional cycling stability [101]. A fibrous carbon nanotube aerogel was synthesized by electrochemical activation and used as an electrode in a supercapacitor. The fibrous CNT-aerogel electrode has a high specific capacitance of $160.8 \mathrm{~F} / \mathrm{g}$ at
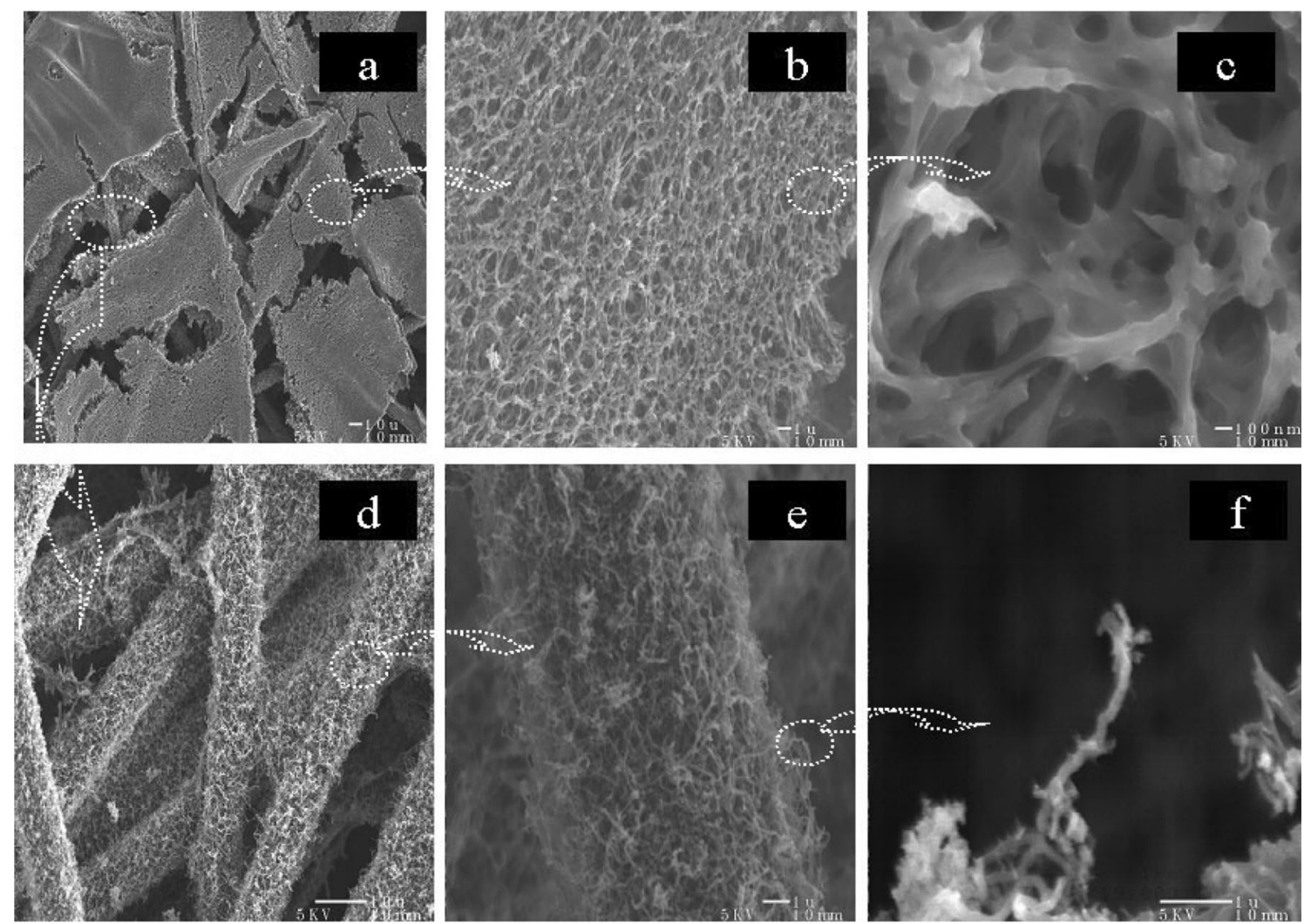

Fig. 9 SEM images of carbon nanotube aerogel Reproduced with permission from [100]

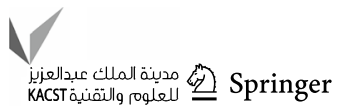




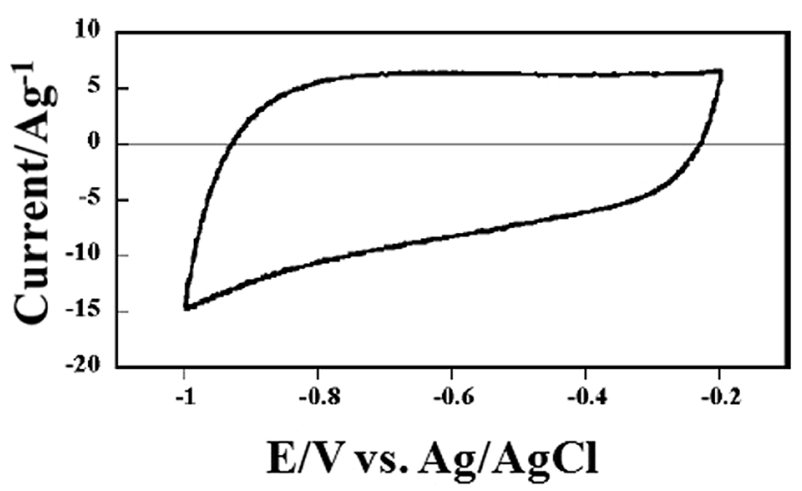

Fig. 10 Cyclic voltammetry of carbon nanotube aerogel in a $5 \mathrm{M}$ $\mathrm{KOH}$ electrolyte; scan rate $20 \mathrm{mV} / \mathrm{s}$. Reproduced with permission from [100]

$0.5 \mathrm{~mA}$ and the specific capacitance was retained after 3000 cycles [102].

\section{Graphene aerogels}

Graphene is a 2-D nanostructure that offers large surface area, tremendous electronic conductivity, mechanical stability and low density [103]. Recently, 3-D nanostructured graphene aerogels were prepared through a self assembling of 2-D graphene nanosheets [104, 105]. Highly conducting graphene aerogel with a BET surface area of $512 \mathrm{~m}^{2} / \mathrm{g}$ was prepared by the reduction of graphene oxide with ascorbic acid. The electrochemical measurements indicate that the graphene aerogels possess a specific capacitance of $128 \mathrm{~F} / \mathrm{g}$ at a constant current density of $50 \mathrm{~mA} / \mathrm{g}$ [106]. Three dimensional self-assembled graphene aerogel was synthesized and used as an anode material in lithium-ion batteries. A higher reversible capacity of $1430 \mathrm{mAh} / \mathrm{g}$ was obtained at a current density of $100 \mathrm{mAh} / \mathrm{g}$ with excellent cycling stability [107].

Lithium-sulfur batteries are being considered as the nextgeneration energy storage devices due to their high theoretical energy density. However, the practical implementation of lithium-sulfur batteries is largely hindered by the insulating properties of sulfur [108]. To improve the electronic conductivity, lithium sulfide $\left(\mathrm{Li}_{2} \mathrm{~S}\right)$ coated graphene aerogel was prepared and used as a cathode in lithium-sulfur batteries. Also, nitrogen and boron-doped graphene aerogels demonstrate fast charge transfer and strong chemical interaction. The $\mathrm{Li}_{2} \mathrm{~S} / \mathrm{N}$ or B doped graphene aerogel cathodes exhibit initial specific capacities of 801 and $720 \mathrm{mAh} / \mathrm{g}$ at $0.3 \mathrm{C}$ rate and after 100 cycles the capacities are maintained at 635 and $532 \mathrm{mAh} / \mathrm{g}$ respectively [109]. Graphene aerogels with different porosities are studied as cathode for $\mathrm{Na}-\mathrm{O}_{2}$ batteries and obtained good cycling performance with 39 cycles at 0.5 $\mathrm{mAh} / \mathrm{cm}^{2}$. They have concluded that the discharge capacity and cyclability of $\mathrm{Na}-\mathrm{O}_{2}$ batteries strongly depend on the pore size of the cathode [110]. Besides, $\mathrm{N}$-doped graphene aerogel was used as an electrode in $\mathrm{Li}$-ion supercapacitor and got a maximum energy density of $70 \mathrm{Wh} / \mathrm{Kg}$ with the power density of $200 \mathrm{Wh} / \mathrm{Kg}$ with good cycling stability [111]. N-doped graphene aerogel was also used as an anode material for microbial fuel cell and attained a power density of $225 \mathrm{~W} / \mathrm{m}^{3}$ with a high open circuit potential of $0.69 \mathrm{~V}$ [112].

Another promising carbon-based aerogel finds applications in energy conversion and storage is carbonitride aerogels. The unusual electronic and optical properties and surprisingly high chemical and thermal stability of carbonitride aerogel make them a superior candidate for photocatalytic application [113]. Recently, carbonitride aerogel was prepared through self-assembly method without using any crosslinking agents. The photocatalytic activity of the carbonitride aerogel was studied water-triethanolamine solution under visible light irradiation. The photocatalyst exhibit a high hydrogen evolution of $30 \mu \mathrm{mol} / \mathrm{h}$ [23].

\section{Polymeric aerogels}

The necessity of materials for aerospace application encompass low density together with exceptional mechanical and thermal insulating properties encouraged the development of polymeric aerogels [114-116]. Borghei et al. fabricated bacterial cellulose (BC), cellulose nanofibers (CNF), chitin nanofibers (ChNF) biopolymer aerogels as electrolytes for quantum dot sensitized solar cells (QDSCs). The power conversion efficiency of $0.5 \%$ was achieved for the bio aerogel based QDSC [117]. A highly porous nanocellulose membrane was used as solid support for the liquid electrolyte iodide/triiodide redox couple in dye solar cells. The short circuit current density is increased by $20 \%$ for nanocellulose based dye solar cells. Solar steam generation by utilizing solar energy through heat localization is a flourishing strategy for sterilization of waste and seawater desalination [118]. Mu et al. synthesized a conjugated microporous polymer aerogel by using a cross-coupling reaction between 1,3 , 5-triethylbenzene and 1, 4-dibromobenzene and 4, 4'-dibromobiphenyl as building blocks. A solar steam generation efficiency of $81 \%$ was achieved at light intensities of $1 \mathrm{~kW} /$ $\mathrm{m}^{2}$ [119].

Generally, aerogel nanostructures are well-known for their insulating property due to air-filled porous network structure. Conversely, the conducting polymer aerogels differ from other aerogels in electrical properties. The conducting polymer aerogel exhibits ordinary properties of aerogels in conjunction with excellent electrical conducting properties [120]. Poly(3,4-ethylenedioxy thiophene) or PEDOT conducting polymer aerogel was obtained by supercritical drying and shows a conductivity of $10^{1} \mathrm{Scm}^{-1}$. The electrochemical capacitance of the PEDOT aerogel was found

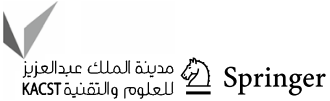


to be $68.5 \mathrm{Fg}^{-1}$ at $50 \mathrm{mV} / \mathrm{s}$ and $48.5 \mathrm{~F} / \mathrm{g}$ at $100 \mathrm{mV} / \mathrm{s}$. Also, the capacitance retained after 100th cycle is $68.1 \mathrm{Fg}^{-1}$ at $50 \mathrm{mV} / \mathrm{s}$ suggests excellent cycling stability [121]. Self crosslinked polyaniline (PAni) aerogels were prepared through the oxidative coupling of aniline hydrochloride using ammonium persulfate as an oxidizing agent. The PAni aerogels have coral-like microstructure as shown in Fig. 11. The PAni aerogel as an electrode in supercapacitor yields a maximum specific capacitance of $750 \mathrm{~F} / \mathrm{g}$ at a current density of $1 \mathrm{~A} / \mathrm{g}$. Moreover, the capacitance is retained when the current density is increased to $2 \mathrm{~A}$ and $20 \mathrm{~A}$ as $588 \mathrm{~F} / \mathrm{g}$ and
446 F/g, respectively. This superior performance indicates an excellent rate capability for high power operation [122].

\section{Application of composite aerogels}

The design of materials with new and improved properties for energy conversion and storage is a great challenge in materials chemistry. However, the development of composite materials by combining two well-known materials with exceptional chemical and physical properties could manage
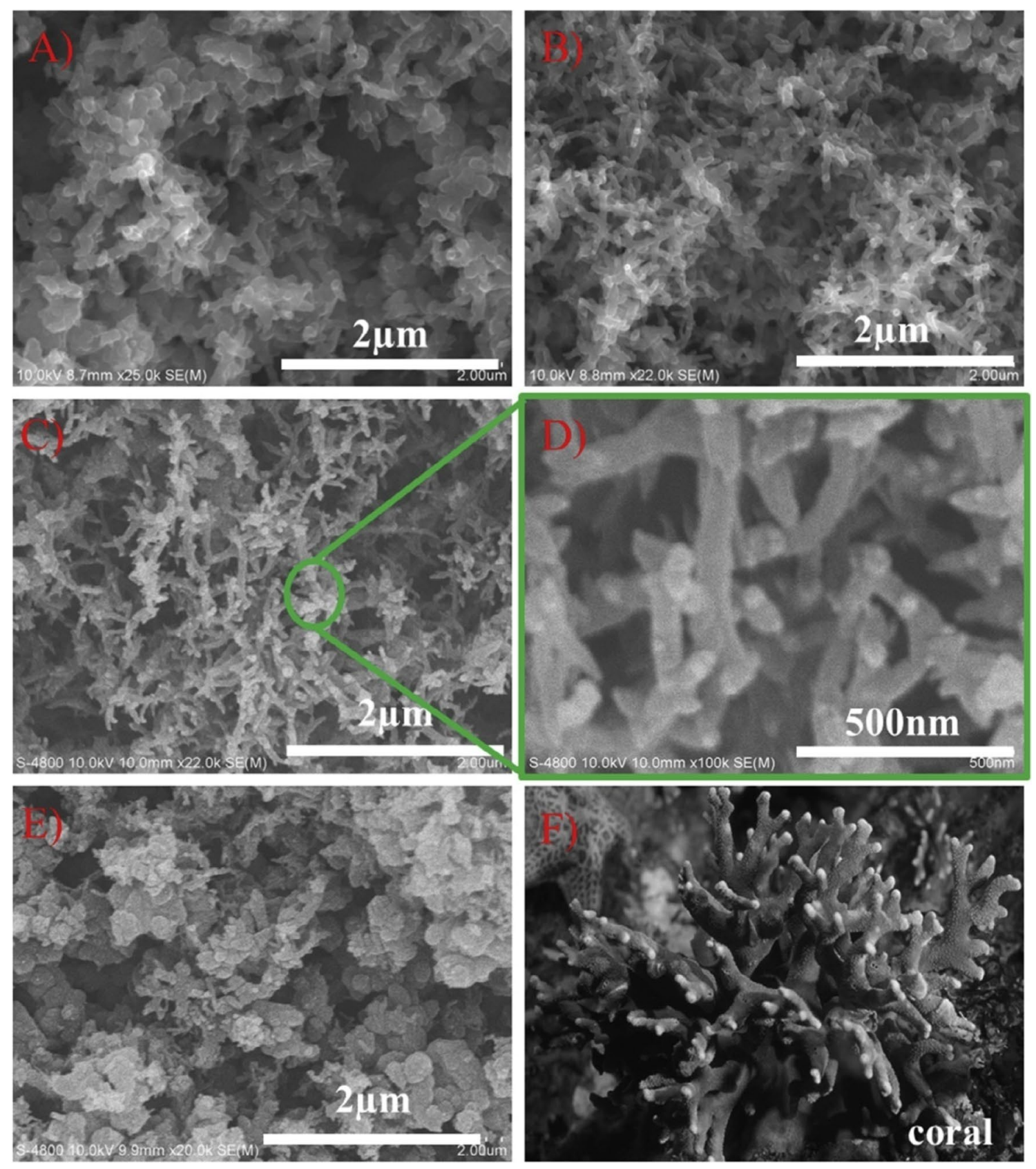

Fig. 11 Morphology of different polyaniline aerogels (a-e) and coral (f). Reproduced with permission from [122] 
this problem [123]. Composite materials consist of two or more constituents with different physical and chemical properties which remain separate and distinct at the microscopic level and the properties of both the constituents are retained in a single physical material $[124,125]$. Anderson et al. developed a method to prepare composite aerogel in which the desired guest is introduced to the sol just before gelation. This prevents the complete encapsulation of guest by aerogel network so that the fascinating of both constituents are retained. Therefore, the use of sol-gel chemistry renders flexibility to design these materials for specific applications [126].

\section{Mixed oxide aerogels}

Mixed oxide aerogels are of special interest due to their high surface acidity, large surface area and thermal stability [127]. $\mathrm{SiO}_{2} / \mathrm{TiO}_{2}$ hybrid aerogel is used as a photoanode material in DSSC and exhibits a power conversion efficiency of $9.41 \%$. The high efficiency is due to the increase in shortcircuit current achieved by high dye loading and light scattering property induced by aerogel microparticles [128]. Gao et al. first synthesized $\mathrm{ZnO}$ aerogels through epoxide initiated sol-gel method followed by supercritical drying [129]. Recently, $\mathrm{ZnO}$ aerogels were synthesized by adopting the same method followed by drying the gel using ambient pressure drying technique. $\mathrm{ZnO} / \mathrm{TiO}_{2}$ mixed aerogel as a bottom layer and $\mathrm{TiO}_{2}$ aerogel overlayer was utilized as photoanode and realized a power conversion efficiency of $0.11 \%$. The reason for a low power conversion efficiency obtained for $\mathrm{ZnO}$ aerogel based photoanode is the dissolution of $\mathrm{ZnO}$ in the dye solution and low surface area of $\mathrm{ZnO}$ [130].

\section{Metal oxide aerogel composites}

Oxide aerogels are doped with metals or non metals to enhance the electronic conducting properties and to improve the visible light activity for increasing their photocatalytic properties [131, 132]. However, the applications of doped oxide aerogels are very scanty in the literature. Correa Baena et al. prepared antimony doped tin oxide aerogels by sol-gel method and supercritical drying with liquid $\mathrm{CO}_{2}$. They have also made atomic layer deposition of $\mathrm{TiO}_{2}$ over aerogel layer with 150 and 300 cycles and employed it as conducting scaffold in DSSCs. The morphology of antimony doped $\mathrm{SnO}_{2}$ aerogels is shown in Fig. 12. They have reported that the electron transport is faster through the aerogel layer which improves the charge collection efficiency [133]. Also, the high surface area, porosity, particle interconnectivity, conductivity and transparency of antimony doped tin oxide aerogels make these nanostructures as attractive porous current collectors for DSSC applications. $\mathrm{Sr}$ and $\mathrm{Zn}$ co-doped $\mathrm{TiO}_{2}$ aerogel was employed as photoanode material for DSSC and shows the highest short circuit current density of $18.75 \mathrm{~mA} /$ $\mathrm{cm}$ and a power conversion efficiency of $7.87 \%$ [134]. $\mathrm{Nb}$,
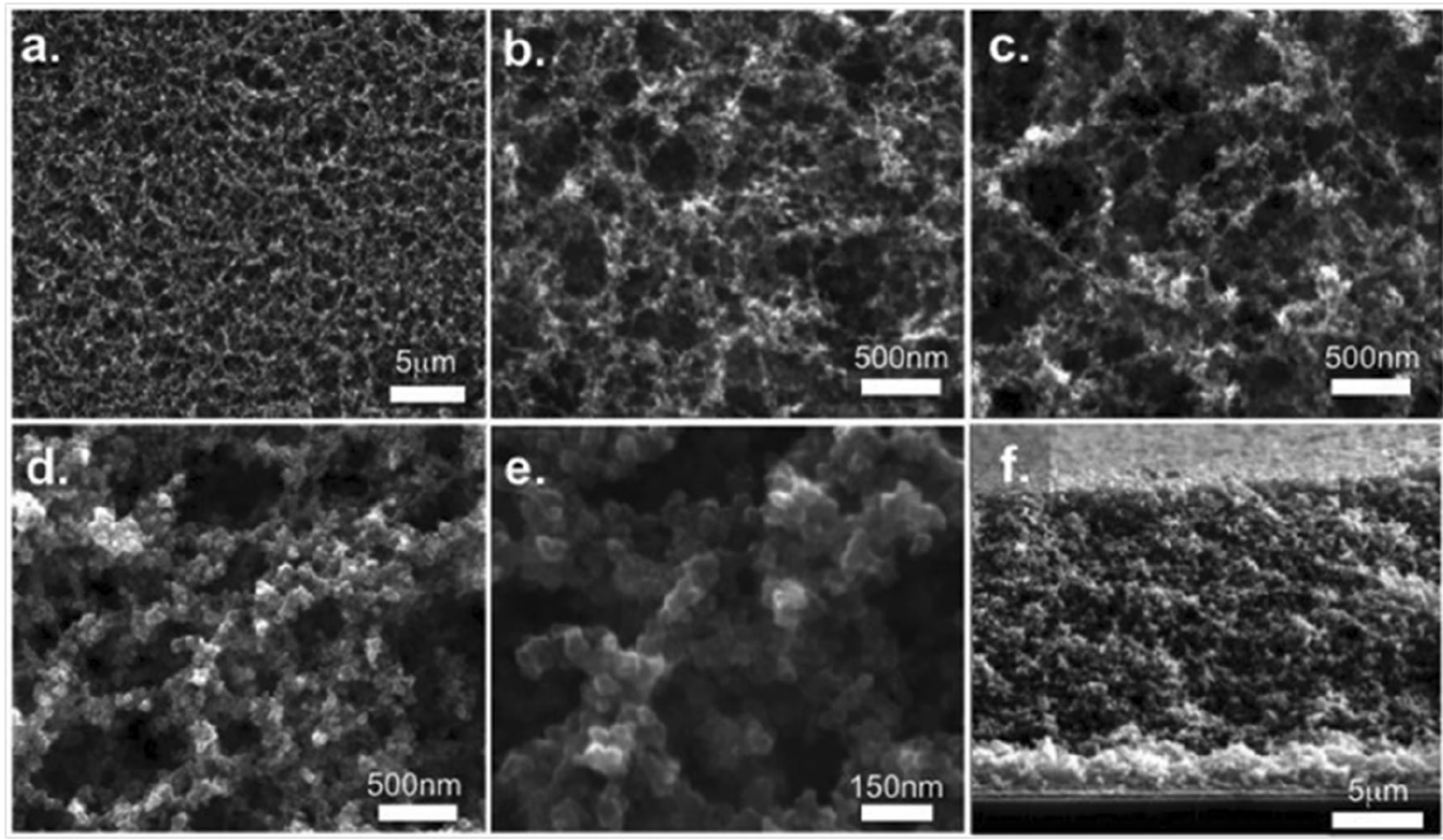

Fig. 12 SEM images of antimony doped tin oxide aerogels at different magnifications (a, b) and aerogel layer with 150 (c) and 300 (d, e) cycles of $\mathrm{TiO}_{2}$ and cross section of the layers (Reproduced with permission from [133]) 
$\mathrm{Ta}, \mathrm{V}$ doped $\mathrm{TiO}_{2}$ aerogels were prepared and employed as catalyst supports for Pt instead of carbon black for proton exchange membrane fuel cell applications. The electronic conductivity of doped aerogel was improved substantially and can be used as catalyst support for fuel cell applications [135].

Pt doped $\mathrm{TiO}_{2}$ aerogels were prepared by polyol and immersion-calcination-reduction methods to increase the hydrogen evolution in photocatalytic water splitting [136]. In another study, Au doped $\mathrm{TiO}_{2}$ aerogel composite exhibits an improved photocatalytic activity towards water splitting reaction due to a more accessible reaction interface and more efficient conversion of excited surface plasmon into charge carriers [137]. Puskelova et al. synthesized $\mathrm{TiO}_{2}-\mathrm{Pt}$ aerogel composites with a high surface area of $162 \mathrm{~m}^{2} \mathrm{~g}^{-1}$ and employed as photocatalyst for the photocatalytic reformation of EtOH and hydrogen production [138]. The highest $\mathrm{H}_{2}$ production rate of $7.2 \mathrm{mmol} / \mathrm{h} / \mathrm{g}$ indicates the high surface area of aerogel nanostructure. $\mathrm{Pt}$ and $\mathrm{N}$ doped $\mathrm{TiO}_{2}$ aerogel was used as a photocatalyst for hydrogen production by electrochemical water splitting [139]. The photocatalytic activity and hydrogen evolution rate were increased with the samples containing higher amounts of nitrogen. The presence of nitrogen in $\mathrm{TiO}_{2}$ aerogel not only increases visible light activity but also creates a synergetic effect between $\mathrm{Pt}$ and nitrogen in $\mathrm{TiO}_{2}$.

Metal organic framework aerogel composites (MOFACs) are a new class of nanostructured materials owing to its high surface area, combined micro and meso porosities and ease of preparation [140]. The fascinating properties of MOFACs composites make them as potential candidates for tissue engineering, drug delivery, catalysis, adsorption, separation, energy conversion and storage as well. Recently, $\mathrm{TiO}_{2}$ aerogel-MOF nanocomposites were synthesized through sol-gel method followed by the ambient pressure drying technique. The nanocomposite materials showed a specific surface area of $250 \mathrm{~m}^{2} / \mathrm{g}$ and used as photoanode material in DSSC. A maximum power conversion efficiency of $2.34 \%$ was achieved with a short circuit current density of $6.22 \mathrm{~mA} /$ $\mathrm{cm}^{2}$ due to high surface area of the composite material which provides more space for the adsorption of more amount dye molecules [141]. However, the power conversion efficiency is slightly lower than that of P25. This is due to inadequate penetration of polymer electrolyte into the pores of aerogelMOF composite and the presence of some oxygen vacancies. $\mathrm{TiO}_{2}$ aerogel-Cu-BTC metal-organic framework composite materials were prepared the photon absorption in the visible region increases with the increase in MOF content in the composite. This property of $\mathrm{TiO}_{2}$ aerogel-Cu-BTC metal-organic framework composite makes the material as promising candidates for photocatalytic and photovoltaic applications [142].

\section{Carbon-based aerogel composites}

Carbon-based aerogel composites attract significant interest pertaining to energy conversion and storage due to their higher electronic conductivity, catalytic activity and hightemperature resistance [143]. The metal-doped carbon aerogel composites are easily prepared by incorporating metal precursor solution to the resorcinol-formaldehyde mixture followed by the polymerization of the resorcinol [144]. Nanosized Ni-doped carbon aerogels with varying amounts of Ni content $(21,35,60$ and $82 \mathrm{wt} \%)$ were prepared and their performance as a supercapacitor electrode was investigated. Carbon aerogel with $35 \mathrm{wt} \% \mathrm{Ni}$ content exhibits a capacitance of $120 \mathrm{~F} / \mathrm{g}$ and excellent charge-discharge behaviour. In addition, $35 \mathrm{wt} \%$ of nanosized $\mathrm{Co}, \mathrm{Cu}, \mathrm{Fe}$ and $\mathrm{Mn}$-doped carbon aerogels were prepared and employed as an electrode in supercapacitor. Among them, Mn-doped carbon aerogel showed the highest capacitance of $141 \mathrm{~F} / \mathrm{g}$ [145]. Cobalt doped carbon aerogels were prepared with different amounts of Co in carbon aerogel and used as an electrode in supercapacitor. The cyclic voltammograms recorded at $10 \mathrm{mV} / \mathrm{s}$ for Co-doped carbon aerogels are presented in the Fig. 13. A maximum specific capacitance of $100 \mathrm{~F} / \mathrm{g}$ was obtained for 7\% Co-doped carbon aerogel [146]. Ruthenium decorated graphene aerogel was synthesized through one-pot hydrothermal method and employed as an electrode material in supercapacitors. The sepcific capacitance of $238 \mathrm{~F} / \mathrm{g}$ at 5 $\mathrm{mV} / \mathrm{s}$ was obtained with better cyclic stability after 15,000 cycles [147]. Transition metal (Fe, $\mathrm{Co}, \mathrm{Ni})$ doped carbon aerogels exhibit high electrocatalytic activity towards oxygen reduction reaction suggests that these composite aerogel materials are better candidates for fuel cell and metal-air battery applications as well [148]. Ni-based electrocatalysts

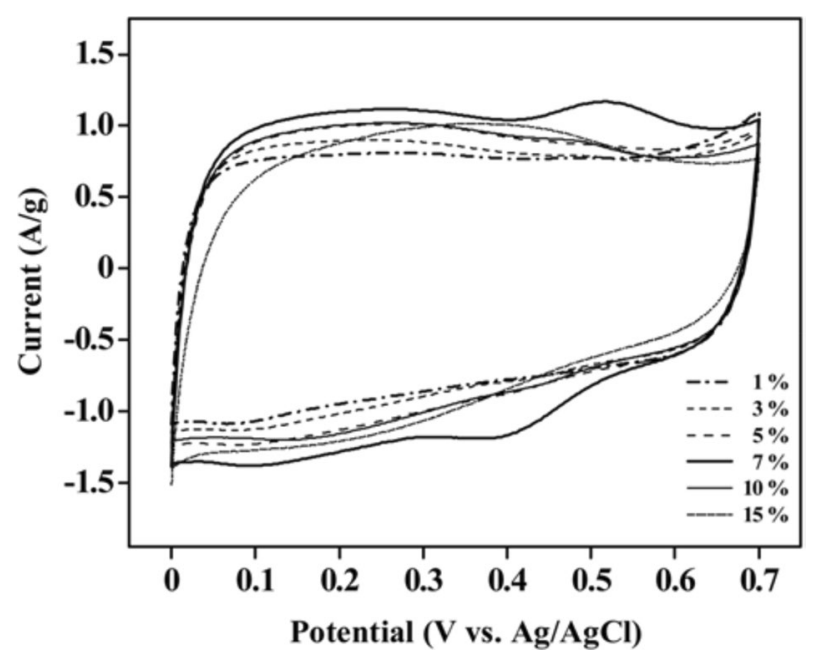

Fig. 13 Cyclic voltammograms of cobalt doped carbon aerogels with different cobalt contents (scan rate $10 \mathrm{mV} / \mathrm{s}$ ). Reproduced with permission from [146] 
have been considered as an efficient anode material for urea fuel cells due to their low cost and high activity towards the urea oxidation reaction. Ni and Co bimetal doped CNT aerogel as an anode electrocatalyst exhibited a maximum power density of $17.5 \mathrm{~mW} / \mathrm{cm}^{2}$ and an open-circuit voltage of $0.9 \mathrm{~V}$ [149]. Here, the metals increased the oxidation peak current and decreased the overpotential of the urea oxidation reaction. The CNT aerogels enhanced the electrocatalytic activity by providing high surface area and better mass transport due to a 3-D network of aerogel structure.

Together with metal doping non metals such as nitrogen, sulphur and boron are also doped in carbon-based aerogels for energy applications. Nitrogen-doped carbon aerogels are promising materials for supercapacitor electrodes and oxygen reduction reaction electrocatalyst due to low cost and high performance [150]. Nitrogen-doped carbon aerogels exhibit a specific capacitance of $124 \mathrm{~F} / \mathrm{g}$ at $20 \mathrm{~A} / \mathrm{g}$ and 467 F/g [151, 152]. Nitrogen-doped graphene aerogels have superior capacitive behaviour of $223 \mathrm{~F} / \mathrm{g}$ and long term cycling performance [153]. Sulphur doped carbon aerogel was used as electrocatalyst for oxygen reduction reaction and found that an excellent tolerance to methanol crossover was detected. The presence of sulphur increases the surface hydrophobicity which enhances the withdrawal of $\mathrm{O}_{2}$ from the electrolyte and its adsorption on the surface. Theses results suggest that sulphur doped carbon aerogel good electrocatalysts for direct methanol fuel cells [154]. Polyaniline coated carbon aerogel-sulphur composites were prepared through melt infiltration of sublimed sulphur into activated carbon aerogel (ACA) followed by in situ polymerization of aniline on the surface of carbon aerogel. The schematic illustration for the synthesis of ACA-500-S@PANi is presented in Fig. 14. The composite material as an electrode in the Li-Sulphur battery delivered a reversible capacity of $1208 \mathrm{mAh} / \mathrm{g}$ at a $0.2 \mathrm{C}$ rate and retains the capacity of 542 $\mathrm{mAh} / \mathrm{g}$ at $3 \mathrm{C}$ rate. Moreover, it delivers a discharge capacity of $926 \mathrm{mAh} / \mathrm{g}$ and excellent capacity retention $66.4 \%$ after 700 cycles at $1 \mathrm{C}$ rate [155]. Iron nitride and nitrogen-doped graphene aerogel composite exhibits comparable activity to $\mathrm{Pt} / \mathrm{C}$ and resistance to methanol crossover [156].

Besides metal and nonmetal doping in carbon-based aerogels, metal oxides are also doped in carbon aerogels for different energy applications. Kalpana et al. prepared a composite electrode by combining high surface area carbon aerogel with large specific capacity $\mathrm{ZnO}$ to deliver faradaic capacitance of the metal oxide and the double-layer capacitance of the carbon aerogel. The capacitance of the composite electrode shows $375 \mathrm{~F} / \mathrm{g}$ at $75 \mathrm{~mA} / \mathrm{cm}^{2}$ indicates the electrochemical capacitive behaviour and stability [157]. Sun et al. fabricated an asymmetric supercapacitor with manganese oxide $(\mathrm{MnO})$ nitrogen-doped carbon aerogel (NCA) composite as a positive electrode and ion oxide $\left(\mathrm{Fe}_{2} \mathrm{O}_{3}\right) / \mathrm{NCA}$ as a negative electrode as shown in Fig. 15. A high specific capacitance of $553 \mathrm{~F} / \mathrm{g}$ was achieved at a scan rate of $10 \mathrm{mV} / \mathrm{s}$. The capacitance values are maintained at $521,478,435$, and $396 \mathrm{~F} / \mathrm{g}$ at a scan rate of 20,50 , $100,200 \mathrm{mV} / \mathrm{s}$ respectively with good rate capability. The enhanced capacitance and rate capability of the composite electrode are attributed to the synergistic effect between conductive carbon aerogel and pseudocapacitive manganese oxide [158]. Transition metal oxides offer low cost, nontoxic, high lithium storage capacity and pseudocapacitive behaviour [159]. However, metal oxide-based anode materials is suffering from mechanical degradation and low electronic conductivity which limits the high rate performance and long term cycling stability of these materials [160]. Consequently, composite materials consisting of metal oxide aerogel and electronically conducting r-GO or CNT was prepared ito solve this problem. Chen et al. developed a simple strategy to fabricate $\mathrm{SnO}_{2}$-rGO aerogel composites for $\mathrm{Li}$ ion battery electrode applications. The composite shows a discharge capacity of $1295 \mathrm{mAh} / \mathrm{g}$ at first cycle and 867 $\mathrm{mAh} / \mathrm{g}$ at 100 th cycle at a current density of $100 \mathrm{~mA} / \mathrm{g}$. The superior electrochemical performance of the composite is due to the large contact surface area of the graphene aerogel with the electrolyte and the uniform distribution of $\mathrm{SnO}_{2}$ nanoparticles [161]. Niederberger et al. fabricated flexible spinel oxide reduced graphene oxide $\left(\mathrm{CoFe}_{2} \mathrm{O}_{4} / \mathrm{r}-\mathrm{GO}\right)$ aerogel nanocomposites and employed as an anode material in Li-ion battery. The composite electrode delivered discharge capacities of $929 \mathrm{mAh} / \mathrm{g}, 1177 \mathrm{mAh} / \mathrm{g}$ and $1290 \mathrm{mAh} / \mathrm{g}$ at $1 \mathrm{C}, 10 \mathrm{C}$ and $60 \mathrm{C}$ rates respectively. The composite electrode delivered a stable capacity of $520 \mathrm{mAh} / \mathrm{g}$ even after 200 cycles at $2 \mathrm{~A} / \mathrm{g}$ [162]. Cobalt ferrite nanoparticle decorated CNT aerogel composite was used as an anode material in lithium-ion battery and enhanced electrochemical performance with a high reversible capacity of $1033 \mathrm{mAh} / \mathrm{g}$ at 0.1 $\mathrm{A} / \mathrm{g}$ and good cycle stability of $874 \mathrm{mAh} / \mathrm{g}$ at $0.1 \mathrm{~A} / \mathrm{g}$ after 160 cycles was achieved [163]. $\mathrm{MoO}_{2} /$ carbon aerogel composite was prepared from seaweed biomass and used as an
Fig. 14 Schematic illustration of the preparation of polyaniline coated carbon aerogel-Sulphur composite. Reproduced with permission from [155]
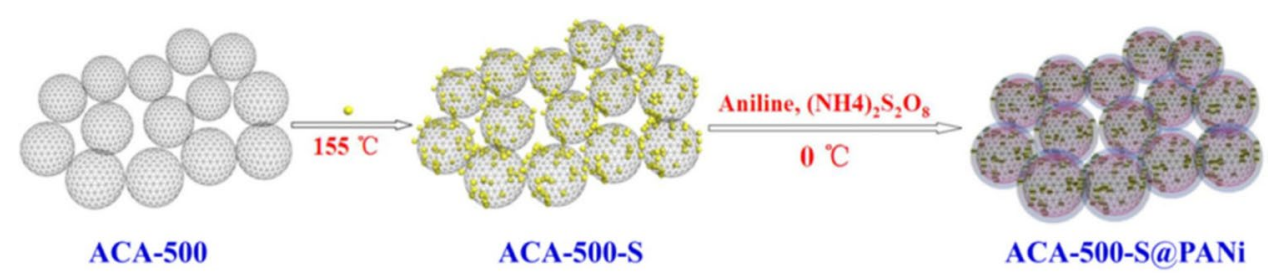


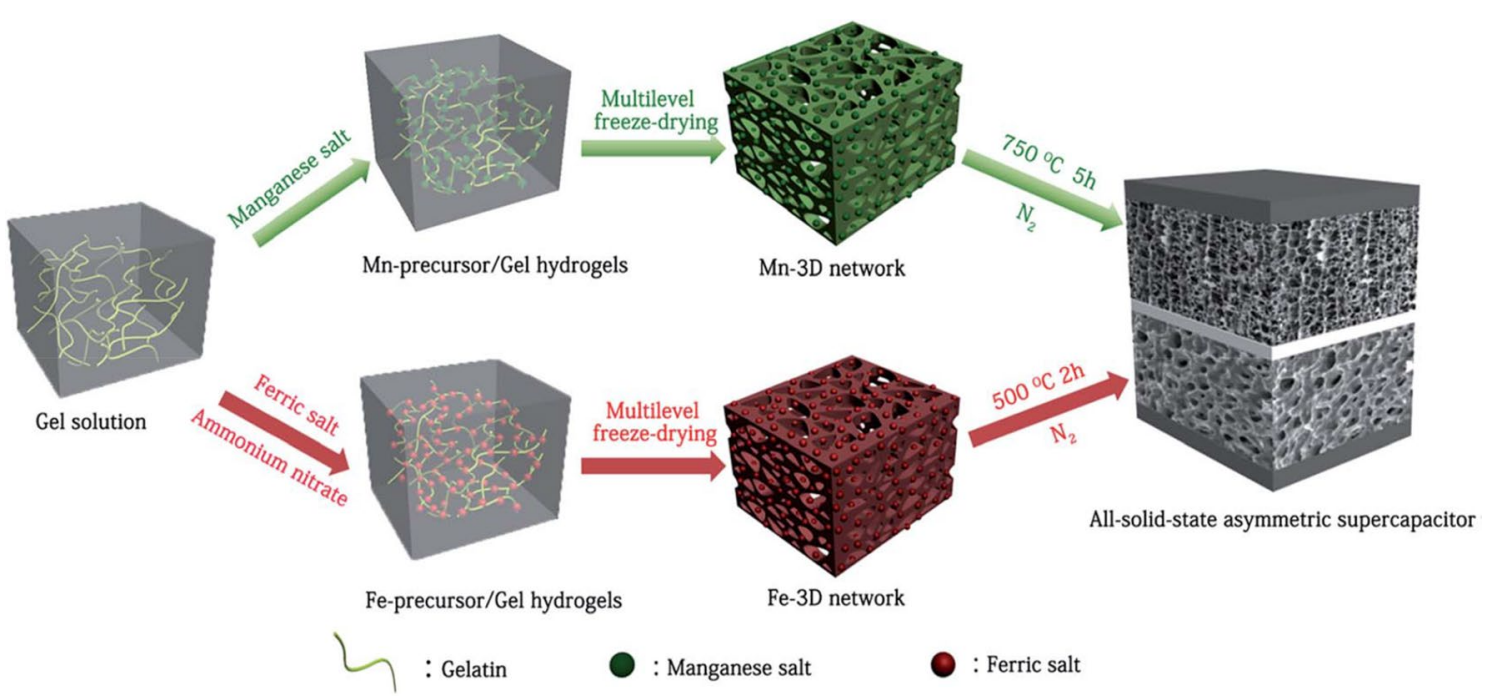

Fig. 15 Schematic illustration of the fabrication process of MnO/NCA as positive electrode and $\mathrm{Fe}_{2} \mathrm{O}_{3}$ / $\mathrm{NCA}$ as negative electrode for construction of asymmetric supercapacitor. Reproduced with permission from [158]

anode material in Li-ion battery. A specific capacity of 574 $\mathrm{mAh} / \mathrm{g}$ at a current density of $100 \mathrm{~mA} / \mathrm{g}$ was obtained with good cycle stability and excellent rate capability [164]. The $\mathrm{MoO}_{2}$ nanoparticles are beneficial for Li-ion transport by increasing the contact area with electrolyte and shortening diffusion length. The carbon aerogel network is capable of accommodating the volume expansion $\mathrm{MoO}_{2}$ nanoparticles during charge/discharge cycles ensures cycling stability. $\mathrm{MoS}_{2}$ decorated carbon aerogel composite was employed as cathode material in lithium-sulfur battery and a high capacity of $1384 \mathrm{mAh} / \mathrm{g}$. A high capacity of $723 \mathrm{mAh} / \mathrm{g}$ at $5 \mathrm{C}$ rate indicating a high rate capability [165]. The enhanced rate capability is due to the interconnected structure of carbon aerogels which offers fast charge transfer kinetics. $\mathrm{CoS}_{2}$ embedded CNT aerogel hybrid was employed as counter electrode material in DSSC [166]. A maximum power conversion efficiency of $8.28 \%$ was obtained for DSSC assembled with a hybrid counter electrode which is higher than that of DSSC assembled with Pt counter electrode (7.2\%).

Carbon-based aerogels are combined with other materials to fabricate composites for specific energy applications. Semiconducting CNT aerogel hybrid was prepared by filling the pores with 6,6-phenyl- $\mathrm{C}_{71}$-butyric acid methyl ester $\left(\mathrm{P}-\mathrm{C}_{71}-\mathrm{BM}\right)$. A bulk heterojunction solar cell fabricated using $\mathrm{CNT}$ aerogel-P- $\mathrm{C}_{71}$-BM hybrid material shows an exceptional power conversion efficiency of $1.7 \%$ [167]. Vanadium tetra sulphide $\left(\mathrm{VS}_{4}\right)$ anchored graphene aerogel was prepared and employed as a cathode material in lithium-ion battery. $\mathrm{VS}_{4}$ anchored graphene aerogel composite exhibits a high reversible capacity of $511 \mathrm{mAhg}^{-1}$ and rate capability of $191 \mathrm{mAh} / \mathrm{g}$ at $5 \mathrm{C}$ rate [168].

Metal-air batteries are blooming electrochemical energy devices which generate electricity through a reaction between a metal and $\mathrm{O}_{2}$ from air on a porous electrode. Highly active and stable electrocatalysts for oxygen reduction reaction and oxygen evolution reaction is essential for rechargeable metal air batteries [169]. Fe and Co immobilized nitrogen-doped carbon aerogel was obtained by initiating the sol-gel polymerization of cyanometalates, chitosan and graphene oxide followed by pyrolysis. The $\mathrm{Zn}$-air battery fabricated using $\mathrm{Fe}$, Co immobilized $\mathrm{N}$ doped carbon aerogel composite as cathode material a maximum power density of $115 \mathrm{~mW} / \mathrm{cm}^{2}$ was obtained with impressive cycling stability [170]. Nitrogen-doped carbon shell encapsulated $\mathrm{Co}_{3} \mathrm{O}_{4}$ nanoparticles were assembled on nitrogen-doped graphene oxide aerogel. The zinc-air battery fabricated using the composite material as cathode exhibits a high voltage of $1.4 \mathrm{~V}$ at $1 \mathrm{~mA} / \mathrm{cm}^{2}$ and a peak power density of $172 \mathrm{~mA} / \mathrm{cm}^{2}$ at $0.56 \mathrm{~V}$ [171].

\section{Other aerogel composites}

Polypyrrole-carbon aerogel composites were prepared through the chemical oxidation polymerization method and used as electrode material in supercapacitor. The composite material has a higher specific capacitance of $433 \mathrm{~F} / \mathrm{g}$ which is higher than the carbon aerogel electrode $(174 \mathrm{~F} / \mathrm{g})$ [172]. Ouyang et al. synthesized a sandwich-like structure of polyaniline-graphene oxide-polyaniline (PANI-GA-PANI) in graphene aerogel beads as illustrated in Fig. 16. This composite material as an electrode in supercapacitor exhibited a specific capacitance of $699 \mathrm{~F} / \mathrm{g}$ with good cyclic stability [173]. Transition metal dichalcogenide $\left(\mathrm{MoS}_{2}, \mathrm{WS}_{2}\right)$ carbon aerogel composites were synthesized with a high surface area of $620 \mathrm{~m}^{2} / \mathrm{g}$ and yields a specific capacitance of $80 \mathrm{~F} / \mathrm{g}$ in supercapacitor [174]. 
Fig. 16 Illustration of the synthesis of graphene oxide aerogel beads and PANI-GO aerogel composite. Reproduced with permission from [173]

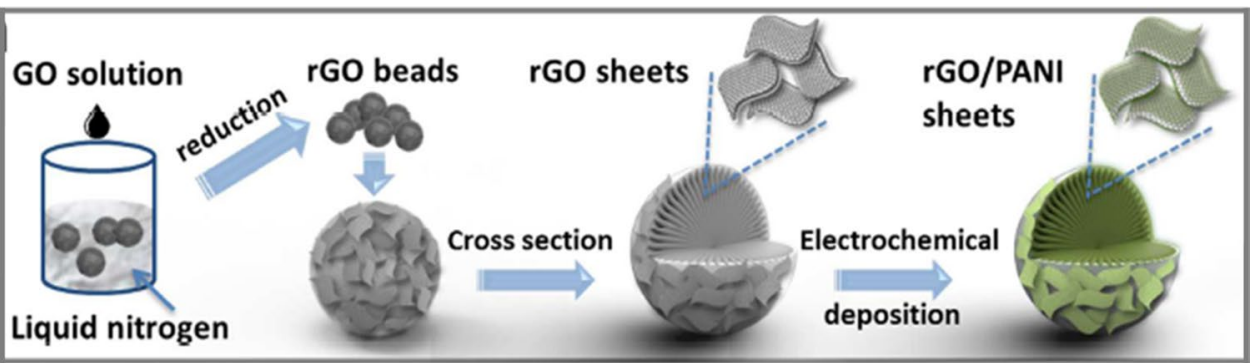

Recently thermoresponsive polymer materials were prepared to address the thermal runaway of electrochemical devices especially lithium-ion batteries. These thermoresponsive polymers work normally at room temperatures of the devices and increase the resistance at unwanted high temperature thus prevent the electronic flow and shut down the device automatically. The polymer composite film has a high electrical conductivity at room temperature due to the quantum tunneling effect enabled by the spiky nanostructure. On heating, the polymer matrix expands and separating the conductive particles, whereas on cooling the polymer matrix shrinks and regains the original conductivity $[175,176]$. The operation of Li-ion battery under normal conditions and in the presence of a thermoresponsive polymer system (TRPS) layer under safe mode is illustrated in Fig. 17. Shi et al. synthesized thermoresponsive hybrid aerogel by in situ crosslinking of phytic acid in poly(N-isopropylacrylamide). The resistance increased to $110 \mathrm{k} \Omega$ within $10 \mathrm{~s}$ after the device is heated demonstrates the high thermoresponsive behaviour of the hybrid aerogel [177]. This interesting result suggests that the aerogel nanostructures not only improves the performance of the electrochemical devices but also increases the safety of the devices. $\mathbf{a}$

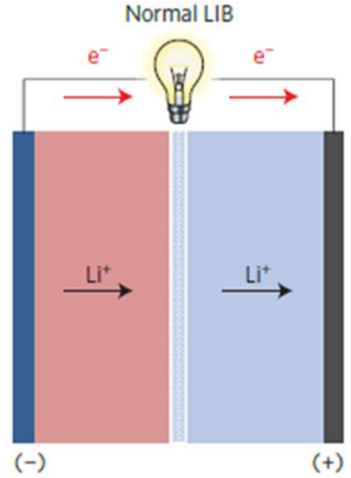

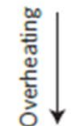

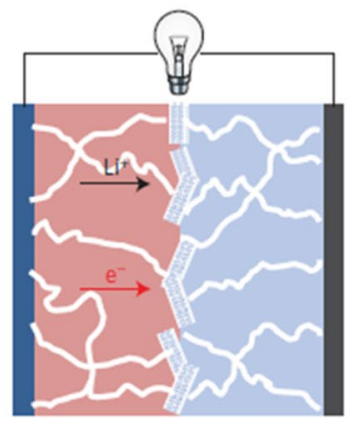

b

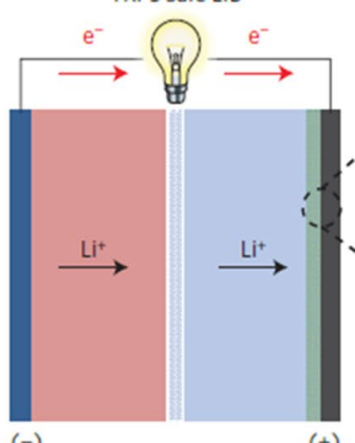

$(-)$

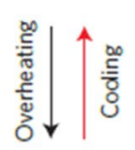

c
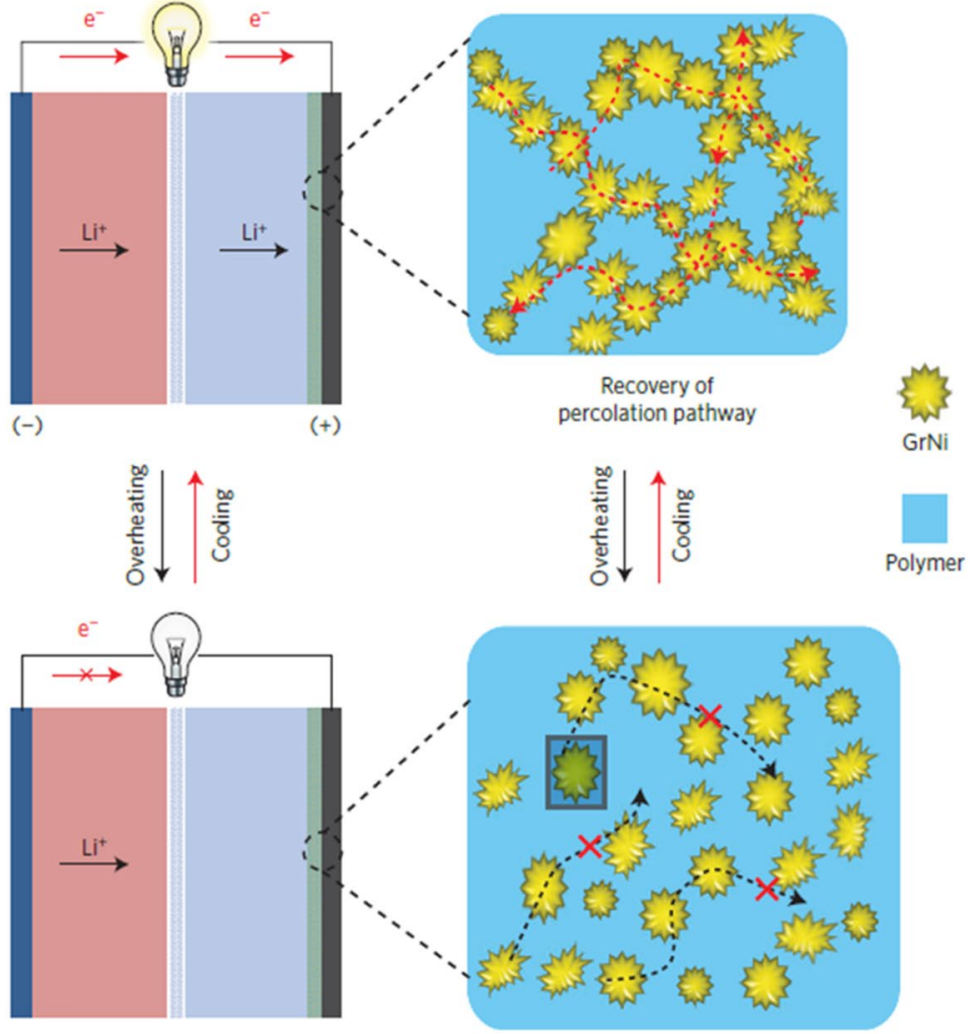

Loss of percolation pathway

Fig. 17 Schematic illustration of Li-ion battery operation $\mathbf{a}$ under normal conditions, $\mathbf{b}$ With TRPS layer under safe mode, $\mathbf{c}$ thermal switching mechanism of TRPS material. Reproduced with permission from [175] 


\section{Conclusions}

In this review, we described the recent developments in the synthesis of aerogel nanostructures with special attention of their application to the fabrication of high-performance energy conversion and storage devices. The attractive structural properties of aerogel put together aerogel as a superior material for battery, solar cell, fuel cell and supercapacitor applications. Therefore, the application of aerogels to energy conversion and storage devices is summarized in three major categories inorganic, organic and composite aerogels. The high surface area and porosity of inorganic oxide aerogels are beneficial for adsorption which is crucial for dye-sensitized solar cells and supercapacitors. Similarly, the high electronic conductivity of organic aerogels is beneficial for supercapacitor applications. But, the composite aerogels obtained by combining the beneficial properties of inorganic and organic materials offer tailored properties for energy conversion and storage devices. Therefore, the composite aerogels are prime candidates for electrochemical device applications because of their outstanding physical and chemical properties.

Though the application of aerogel nanostructures are studied well in lab scale, there are some challenges in the commercialization of this material. For example, the timeconsuming solvent exchange process and low electronic conductivity of aerogel nanostructures prevent their commercial success in energy conversion and storage devices. Therefore, simplified synthetic strategies by reducing the time for solvent exchange will be studied intensively in the coming years. Moreover, to attain high electronic conductivity, synthesis of composite aerogels will flourish in the near future since it combines the benefits of the porous network structure of aerogels and electronic properties of conducting materials. Particularly, synthesis of composite aerogels with high electronic conducting materials such as graphene, CNT and conducting polymers or electronically insulating metal-organic frameworks (MOFs), to accomplish the specific requirements for energy conversion and storage applications. The physical and chemical modification of aerogel surface to improve the adsorption process as well seems to have great potential in the future. On the other hand, the development of metallic and multimetallic aerogel networks and their deposition on the surface of electronically conducting aerogels (composite aerogels) will receive much attention in the forthcoming years, to achieve exceptionally high electrocatalytic properties and durability for fuel cell applications. Certainly, aerogel nanostructures are sustainable materials for the fabrication of energy conversion and storage devices.

Acknowledgements The authors gratefully acknowledge the financial support from the Board of Research in Nuclear Sciences
(BRNS), Department of Atomic Energy, Govt. of India (Sanction No. 2013/34/15/BRNS/1123) and Science and Engineering Research Board (SERB), Department of Science and Technology, Govt. of India (Sanction No. EMR/2014/000416).

Open Access This article is licensed under a Creative Commons Attribution 4.0 International License, which permits use, sharing, adaptation, distribution and reproduction in any medium or format, as long as you give appropriate credit to the original author(s) and the source, provide a link to the Creative Commons licence, and indicate if changes were made. The images or other third party material in this article are included in the article's Creative Commons licence, unless indicated otherwise in a credit line to the material. If material is not included in the article's Creative Commons licence and your intended use is not permitted by statutory regulation or exceeds the permitted use, you will need to obtain permission directly from the copyright holder. To view a copy of this licence, visit http://creativecommons.org/licenses/by/4.0/.

\section{References}

1. Li, K., Lin, B.: Impacts of urbanization and industrialization on energy consumption/ $\mathrm{CO}_{2}$ emissions: Does the level of development matter? Renew. Sustain. Energy Rev. 52, 1107-1122 (2015)

2. Mao, S.S., Chen, X.: Selected nanotechnologies for renewable energy applications. Int. J. Energy Res. 31(6-7), 619-636 (2007)

3. Acar, C., Dincer, I., Naterer, G.F.: Review of photocatalytic water-splitting methods for sustainable hydrogen production. Int. J. Energy Res. 40(11), 1449-1473 (2016)

4. Le, N.L., Nunes, S.P.: Materials and membrane technologies for water and energy sustainability. Sustain. Mater. Technol. 7, 1-28 (2016)

5. Badwal, S.P., Giddey, S.S., Munnings, C., Bhatt, A.I., Hollenkamp, A.F.: Emerging electrochemical energy conversion and storage technologies. Front. Chem. 2, 79 (2014)

6. Aricò, A.S., Bruce, P., Scrosati, B., Tarascon, J.-M., Van Schalkwijk, W.: Nanostructured materials for advanced energy conversion and storage devices. Nat. Mater. 4(5), 366-377 (2005)

7. Chen, G., Seo, J., Yang, C., Prasad, P.N.: Nanochemistry and nanomaterials for photovoltaics. Chem. Soc. Rev. 42(21), 83048338 (2013)

8. Zhang, Q., Uchaker, E., Candelaria, S.L., Cao, G.: Nanomaterials for energy conversion and storage. Chem. Soc. Rev. 42(7), 3127-3171 (2013)

9. Xu, J., Wang, X., Wang, X., Chen, D., Chen, X., Li, D., Shen, G.: Three-dimensional structural engineering for energy-storage devices: from microscope to macroscope. ChemElectroChem 1(6), 975-1002 (2014)

10. Hüsing, N., Schubert, U.: Aerogels-airy materials: chemistry, structure and properties. Angew. Chem. 110(1-2), 22-47 (1998)

11. Du, A., Zhou, B., Zhang, Z., Shen, J.: A special material or a new state of matter: a review and reconsideration of the aerogel. Materials 6(3), 941-968 (2013)

12. Jones, S.M.: Aerogel: space exploration applications. J. Sol-Gel. Sci. Technol. 40(2-3), 351-357 (2006)

13. Hrubesh, L.W.: Aerogel applications. J. Non-Cryst.Solids 225, 335-342 (1998)

14. Ulker, Z., Erkey, C.: An emerging platform for drug delivery: Aerogel based systems. J. Control. Release 177, 51-63 (2014)

15. Tétreault, N., Grätzel, M.: Novel nanostructures for next generation dye-sensitized solar cells. Energy Environ. Sci. 5(9), 8506-8516 (2012) 
16. Ellis, B.L., Knauth, P., Djenizian, T.: Three-dimensional selfsupported metal oxides for advanced energy storage. Adv. Mater. 26(21), 3368-3397 (2014)

17. Rechberger, F., Niederberger, M.: Synthesis of aerogels: from molecular routes to 3-dimensional nanoparticle assembly. Nanoscale Horiz. 2(1), 6-30 (2017)

18. Hüsing, N., Schubert, U.: Aerogels-airy materials: chemistry, structure, and properties. Angew. Chem. Int. Ed. 37(1-2), 22-45 (1998)

19. Norris, P.M., Shrinivasan, S.: Aerogels: unique material, fascinating properties and unlimited applications. Annu. Rev. Heat Transfer 14, 14 (2005)

20. Mirkin, C.A., Letsinger, R.L., Mucic, R.C., Storhoff, J.J.: A DNA-based method for rationally assembling nanoparticles into macroscopic materials. Nature 382(6592), 607-609 (1996)

21. Boal, A.K., Ilhan, F., DeRouchey, J.E., Thurn-Albrecht, T., Russell, T.P., Rotello, V.M.: Self-assembly of nanoparticles into structured spherical and network aggregates. Nature 404(6779), 746-748 (2000)

22. Brock, S.L., Arachchige, I.U., Kalebaila, K.K.: Metal chalcogenide gels, xerogels and aerogels. Comments Inorg. Chem. 27(5-6), 103-126 (2006)

23. Ou, H., Yang, P., Lin, L., Anpo, M., Wang, X.: Carbon nitride aerogels for the photoredox conversion of water. Angew. Chem. Int. Ed. 56(36), 10905-10910 (2017)

24. Alnaief, M., Smirnova, I.: In situ production of spherical aerogel microparticles. J. Supercrit. Fluids 55(3), 1118-1123 (2011)

25. Alnaief, M., Alzaitoun, M., García-González, C., Smirnova, I.: Preparation of biodegradable nanoporous microspherical aerogel based on alginate. Carbohyd. Polym. 84(3), 1011-1018 (2011)

26. García-González, C., Uy, J., Alnaief, M., Smirnova, I.: Preparation of tailor-made starch-based aerogel microspheres by the emulsion-gelation method. Carbohyd. Polym. 88(4), 1378-1386 (2012)

27. Farahani, R.D., Dubé, M., Therriault, D.: Three-dimensional printing of multifunctional nanocomposites: manufacturing techniques and applications. Adv. Mater. 28(28), 5794-5821 (2016)

28. Ambrosi, A., Pumera, M.: 3D-printing technologies for electrochemical applications. Chem. Soc. Rev. 45(10), 2740-2755 (2016)

29. Barrios, E., Fox, D., Li Sip, Y.Y., Catarata, R., Calderon, J.E., Azim, N., Afrin, S., Zhang, Z., Zhai, L.: Nanomaterials in advanced, high-performance aerogel composites: a review. Polymers 11(4), 726 (2019)

30. Tang, X., Zhu, C., Cheng, D., Zhou, H., Liu, X., Xie, P., Zhao, Q., Zhang, D., Fan, T.: Architectured leaf-inspired Ni0. 33Co0. 66S2/graphene aerogels via 3D printing for high-performance energy storage. Adv. Funct. Mater. 28(51), 1805057 (2018)

31. Way, A.E., Hsu, L., Shanmuganathan, K., Weder, C., Rowan, S.J.: pH-responsive cellulose nanocrystal gels and nanocomposites. ACS Macro Lett. 1(8), 1001-1006 (2012)

32. Li, V.C.-F., Dunn, C.K., Zhang, Z., Deng, Y., Qi, H.J.: Direct ink write (DIW) 3D printed cellulose nanocrystal aerogel structures. Sci.Rep. 7(1), 1-8 (2017)

33. Garnweitner, G., Niederberger, M.: Organic chemistry in inorganic nanomaterials synthesis. J. Mater. Chem. 18(11), 1171$1182(2008)$

34. Schaefer, D.T., Keefer, K.: Fractal geometry of silica condensation polymers. Phys.Rev.Lett. 53(14), 1383 (1984)

35. Keefer, K., Schaefer, D.: Growth of fractally rough colloids. Phys. Rev. Lett. 56(22), 2376 (1986)

36. Brinker, C., Keefer, K., Schaefer, D., Ashley, C.: Sol-gel transition in simple silicates. J. Non-Cryst. Solids 48(1), 47-64 (1982)

37. Lu, Z., Yin, Y.: Colloidal nanoparticle clusters: functional materials by design. Chem. Soc. Rev. 41(21), 6874-6887 (2012)
38. Deshpande, A.S., Pinna, N., Smarsly, B., Antonietti, M., Niederberger, M.: Controlled assembly of preformed ceria nanocrystals into highly ordered 3D nanostructures. Small 1(3), 313-316 (2005)

39. Polleux, J., Antonietti, M., Niederberger, M.: Ligand and solvent effects in the nonaqueous synthesis of highly ordered anisotropic tungsten oxide nanostructures. J. Mater. Chem. 16(40), 39693975 (2006)

40. Pierre, A.C., Pajonk, G.M.: Chemistry of aerogels and their applications. Chem. Rev. 102(11), 4243-4266 (2002)

41. Sui, R., Charpentier, P.: Synthesis of metal oxide nanostructures by direct sol-gel chemistry in supercritical fluids. Chem. Rev. 112(6), 3057-3082 (2012)

42. Tewari, P.H., Hunt, A.J., Lofftus, K.D.: Ambient-temperature supercritical drying of transparent silica aerogels. Mater. Lett. 3(9-10), 363-367 (1985)

43. Sui, R., Rizkalla, A., Charpentier, P.A.: Experimental study on the morphology and porosity of $\mathrm{TiO}_{2}$ aerogels synthesized in supercritical carbon dioxide. Microporous Mesoporous Mater. 142(2), 688-695 (2011)

44. Štengl, V., Bakardjieva, S., Šubrt, J., Szatmary, L.: Titania aerogel prepared by low temperature supercritical drying. Microporous Mesoporous Mater. 91(1), 1-6 (2006)

45. Aravind, P., Shajesh, P., Soraru, G., Warrier, K.: Ambient pressure drying: a successful approach for the preparation of silica and silica based mixed oxide aerogels. J. Sol-Gel. Sci. Technol. 54(1), 105-117 (2010)

46. Deshpande, R., Smith, D.M., Brinker, C.J., in, Google Patents (1996)

47. Smith, D.M., Stein, D., Anderson, J.M., Ackerman, W.: Preparation of low-density xerogels at ambient pressure. J. NonCryst. Solids 186, 104-112 (1995)

48. Kumar, S.R., Pillai, P.K., Warrier, K.: Synthesis of high surface area silica by solvent exchange in alkoxy derived silica gels. Polyhedron 17(10), 1699-1703 (1998)

49. Ren, L., Cui, S., Cao, F., Guo, Q.: An easy way to prepare monolithic inorganic oxide aerogels. Angew. Chem. Int. Ed. 53(38), 10147-10149 (2014)

50. Kistler, S.S.: Coherent expanded aerogels and jellies. Nature 127, 741 (1931)

51. Pinchuk, O.A., Dundar, F., Ata, A., Wynne, K.J.: Improved thermal stability, properties, and electrocatalytic activity of sol-gel silica modified carbon supported Pt catalysts. Int. J. Hydrogen Energy 37(3), 2111-2120 (2012)

52. Tsai, C.-H., Yang, F.-L., Chang, C.-H., Chen-Yang, Y.W.: Microwave-assisted synthesis of silica aerogel supported pt nanoparticles for self-humidifying proton exchange membrane fuel cell. Int. J. Hydrogen Energy 37(9), 7669-7676 (2012)

53. Teichner, S., Nicolaon, G., Vicarini, M., Gardes, G.: Inorganic oxide aerogels. Adv. Coll. Interface. Sci. 5(3), 245-273 (1976)

54. Jena, A., Mohanty, S.P., Kumar, P., Naduvath, J., Gondane, V., Lekha, P., Das, J., Narula, H.K., Mallick, S., Bhargava, P.: Dye sensitized solar cells: a review. Trans. Indian Ceram. Soc. 71(1), 1-16 (2012)

55. Baia, L., Peter, A., Cosoveanu, V., Indrea, E., Baia, M., Popp, J., Danciu, V.: Synthesis and nanostructural characterization of $\mathrm{TiO}_{2}$ aerogels for photovoltaic devices. Thin Solid Films 511, 512-516 (2006)

56. Pietron, J.J., Stux, A.M., Compton, R.S., Rolison, D.R.: Dyesensitized titania aerogels as photovoltaic electrodes for electrochemical solar cells. Sol. Energy Mater. Sol. Cells 91(12), 1066-1074 (2007)

57. Chiang, Y.-C., Cheng, W.-Y., Lu, S.-Y.: Titania aerogels as a superior mesoporous structure for photoanodes of dye-sensitized solar cells. Int. J. Electrochem. Sci 7, 6910-6919 (2012)

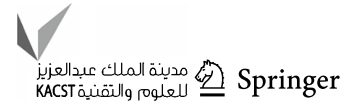


58. Alwin, S., Shajan, X.S., Menon, R., Nabhiraj, P., Warrier, K., Rao, G.M.: Surface modification of titania aerogel films by oxygen plasma treatment for enhanced dye adsorption. Thin Solid Films 595, 164-170 (2015)

59. Alwin, S., Menon, R., Nabhiraj, P., Ananthapadmanabhan, P.: Plasma treated $\mathrm{TiO} 2$ aerogel nanostructures as photoanode material and its influence on the performance of quasisolid dye-sensitized solar cells. Mater. Res. Bull. 86, 201-208 (2017)

60. Alwin, S., Shajan, X.S., Karuppasamy, K., Warrier, K.: Microwave assisted synthesis of high surface area $\mathrm{TiO} 2$ aerogels: a competent photoanode material for quasi-solid dye-sensitized solar cells. Mater. Chem. Phys. 196, 37-44 (2017)

61. Heimböckel, R., Hoffmann, F., Fröba, M.: Insights into the influence of the pore size and surface area of activated carbons on the energy storage of electric double layer capacitors with a new potentially universally applicable capacitor model. Phys. Chem. Chem. Phys. 21(6), 3122-3133 (2019)

62. Sharma, V., Singh, I., Chandra, A.: Hollow nanostructures of metal oxides as next generation electrode materials for supercapacitors. Sci. Rep. 8(1), 1-12 (2018)

63. Lin, C., Ritter, J.A., Popov, B.N.: Characterization of sol-gelderived cobalt oxide xerogels as electrochemical capacitors. J. Electrochem. Soc. 145(12), 4097-4103 (1998)

64. Wei, T.-Y., Chen, C.-H., Chang, K.-H., Lu, S.-Y., Hu, C.-C.: Cobalt oxide aerogels of ideal supercapacitive properties prepared with an epoxide synthetic route. Chem. Mater. 21(14), 3228-3233 (2009)

65. Moretti, A., Secchiaroli, M., Buchholz, D., Giuli, G., Marassi, R., Passerini, S.: Exploring the low voltage behavior of V2O5 aerogel as intercalation host for sodium ion battery. J. Electrochem. Soc. 162(14), A2723-A2728 (2015)

66. Moretti, A., Maroni, F., Osada, I., Nobili, F., Passerini, S.: V2O5 aerogel as a versatile cathode material for lithium and sodium batteries. ChemElectroChem 2(4), 529-537 (2015)

67. Maloney, R.P., Kim, H.J., Sakamoto, J.S.: Lithium titanate aerogel for advanced lithium-ion batteries. ACS Appl. Mater. Interfaces. 4(5), 2318-2321 (2012)

68. Mohanan, J.L., Arachchige, I.U., Brock, S.L.: Porous semiconductor chalcogenide aerogels. Science 307(5708), 397-400 (2005)

69. Arachchige, I.U., Brock, S.L.: Sol-gel assembly of Cdse nanoparticles to form porous aerogel networks. J. Am. Chem. Soc. 128(24), 7964-7971 (2006)

70. Leventis, N.: Three-dimensional core-shell superstructures: mechanically strong aerogels. Acc. Chem. Res. 40(9), 874-884 (2007)

71. Mahadik-Khanolkar, S., Donthula, S., Bang, A., Wisner, C., Sotiriou-Leventis, C., Leventis, N.: Polybenzoxazine aerogels. 2. Interpenetrating networks with iron oxide and the carbothermal synthesis of highly porous monolithic pure iron (0) aerogels as energetic materials. Chem. Mater. 26(3), 1318-1331 (2014)

72. Bigall, N.C., Herrmann, A.K., Vogel, M., Rose, M., Simon, P., Carrillo-Cabrera, W., Dorfs, D., Kaskel, S., Gaponik, N., Eychmüller, A.: Hydrogels and aerogels from noble metal nanoparticles. Angew. Chem. Int. Ed. 48(51), 9731-9734 (2009)

73. Liu, W., Herrmann, A.-K., Bigall, N.C., Rodriguez, P., Wen, D., Oezaslan, M., Schmidt, T.J., Gaponik, N., Eychmüller, A.: Noble metal aerogels synthesis, characterization, and application as electrocatalysts. Acc. Chem. Res. 48(2), 154-162 (2015)

74. Herrmann, A.-K., Formanek, P., Borchardt, L., Klose, M., Giebeler, L., Eckert, J.R., Kaskel, S., Gaponik, N., Eychmüller, A.: Multimetallic aerogels by template-free self-assembly of $\mathrm{Au}, \mathrm{Ag}$, $\mathrm{Pt}$, and Pd nanoparticles. Chem. Mater. 26(2), 1074-1083 (2013)

75. Liu, W., Herrmann, A.K., Geiger, D., Borchardt, L., Simon, F., Kaskel, S., Gaponik, N., Eychmüller, A.: High-performance electrocatalysis on palladium aerogels. Angew. Chem. Int. Ed. 51(23), 5743-5747 (2012)

76. Yazdan-Abad, M.Z., Noroozifar, M., Alam, A.R.M., Saravani, H.: Palladium aerogel as a high-performance electrocatalyst for ethanol electro-oxidation in alkaline media. J. Mater. Chem. A 5(21), 10244-10249 (2017)

77. Wen, D., Liu, W., Haubold, D., Zhu, C., Oschatz, M., Holzschuh, M., Wolf, A., Simon, F., Kaskel, S., Eychmüller, A.: Gold aerogels: three-dimensional assembly of nanoparticles and their use as electrocatalytic interfaces. ACS Nano 10(2), 2559-2567 (2016)

78. Debe, M.K.: Electrocatalyst approaches and challenges for automotive fuel cells. Nature 486(7401), 43 (2012)

79. Henning, S., Kühn, L., Herranz, J., Durst, J., Binninger, T., Nachtegaal, M., Werheid, M., Liu, W., Adam, M., Kaskel, S.: $\mathrm{Pt}-\mathrm{Ni}$ aerogels as unsupported electrocatalysts for the oxygen reduction reaction. J. Electrochem. Soc. 163(9), F998-F1003 (2016)

80. Stamenkovic, V.R., Mun, B.S., Arenz, M., Mayrhofer, K.J., Lucas, C.A., Wang, G., Ross, P.N., Markovic, N.M.: Trends in electrocatalysis on extended and nanoscale Pt-bimetallic alloy surfaces. Nat. Mater. 6(3), 241-247 (2007)

81. Henning, S., Shimizu, R., Herranz, J., Kühn, L., Eychmüller, A., Uchida, M., Kakinuma, K., Schmidt, T.J.: Unsupported Pt3Ni aerogels as corrosion resistant PEFC anode catalysts under gross fuel starvation conditions. J. Electrochem. Soc. 165(6), F3001F3006 (2018)

82. Zhu, C., Shi, Q., Fu, S., Song, J., Xia, H., Du, D., Lin, Y.: Efficient synthesis of $\mathrm{MCu}(\mathrm{M}=\mathrm{Pd}, \mathrm{Pt}$, and $\mathrm{Au})$ aerogels with accelerated gelation kinetics and their high electrocatalytic activity. Adv. Mater. 28(39), 8779-8783 (2016)

83. Biener, J., Stadermann, M., Suss, M., Worsley, M.A., Biener, M.M., Rose, K.A., Baumann, T.F.: Advanced carbon aerogels for energy applications. Energy Environ. Sci. 4(3), 656-667 (2011)

84. Pekala, R.: Organic aerogels from the polycondensation of resorcinol with formaldehyde. J. Mater. Sci. 24(9), 3221-3227 (1989)

85. Mayer, S., Pekala, R., Kaschmitter, J.: The aerocapacitor: an electrochemical double-layer energy-storage device. J. Electrochem. Soc. 140(2), 446-451 (1993)

86. Pekala, R., Farmer, J., Alviso, C., Tran, T., Mayer, S., Miller, J., Dunn, B.: Carbon aerogels for electrochemical applications. J. Non-crystall. Solids 225, 74-80 (1998)

87. Pröbstle, H., Schmitt, C., Fricke, J.: Button cell supercapacitors with monolithic carbon aerogels. J. Power Sources 105(2), 189-194 (2002)

88. Zhu, Y., Hu, H., Li, W.-C., Zhang, X.: Cresol-formaldehyde based carbon aerogel as electrode material for electrochemical capacitor. J. Power Sources 162(1), 738-742 (2006)

89. Li, J., Wang, X., Huang, Q., Gamboa, S., Sebastian, P.: Studies on preparation and performances of carbon aerogel electrodes for the application of supercapacitor. J. Power Sources 158(1), 784-788 (2006)

90. Zapata-Benabithe, Z., Diossa, G., Castro, C.D., Quintana, G.: Activated carbon bio-xerogels as electrodes for super capacitors applications. Proc. Eng. 148, 18-24 (2016)

91. Xu, X., Zhou, J., Nagaraju, D.H., Jiang, L., Marinov, V.R., Lubineau, G., Alshareef, H.N., Oh, M.: Flexible, highly graphitized carbon aerogels based on bacterial cellulose/lignin: catalyst-free synthesis and its application in energy storage devices. Adv. Funct. Mater. 25(21), 3193-3202 (2015)

92. Xu, J., Zhou, X., Chen, M., Shi, S., Cao, Y.: Preparing hierarchical porous carbon aerogels based on enzymatic hydrolysis lignin through ambient drying for supercapacitor electrodes. Microporous and Mesoporous Mater. 265, 258-265 (2018) 
93. Smirnova, A., Dong, X., Hara, H., Vasiliev, A., Sammes, N.: Novel carbon aerogel-supported catalysts for PEM fuel cell application. Int. J. Hydrogen Energy 30(2), 149-158 (2005)

94. Marie, J., Chenitz, R., Chatenet, M., Berthon-Fabry, S., Cornet, N., Achard, P.: Highly porous PEM fuel cell cathodes based on low density carbon aerogels as Pt-support: experimental study of the mass-transport losses. J. Power Sources 190(2), 423-434 (2009)

95. Guilminot, E., Fischer, F., Chatenet, M., Rigacci, A., BerthonFabry, S., Achard, P., Chainet, E.: Use of cellulose-based carbon aerogels as catalyst support for PEM fuel cell electrodes: electrochemical characterization. J. Power Sources 166(1), 104-111 (2007)

96. Yang, X., Wei, C., Zhang, G.: Activated carbon aerogels with developed mesoporosity as high-rate anodes in lithium-ion batteries. J. Mater. Sci. 51(11), 5565-5571 (2016)

97. Wang, L., Schütz, C., Salazar-Alvarez, G., Titirici, M.-M.: Carbon aerogels from bacterial nanocellulose as anodes for lithium ion batteries. Rsc Adv. 4(34), 17549-17554 (2014)

98. Chen, K., Huang, X., Zhang, Z., Du, A., Zhou, B., Xu, Y., Zhou, Z., Wang, Y.: Low temperature pseudomorphic synthesis of nanocrystalline carbide aerogels for electrocatalysis. J. Mater. Chem. A 3(22), 11745-11749 (2015)

99. Bryning, M.B., Milkie, D.E., Islam, M.F., Hough, L.A., Kikkawa, J.M., Yodh, A.G.: Carbon nanotube aerogels. Adv. Mater. 19(5), 661-664 (2007)

100. Bordjiba, T., Mohamedi, M., Dao, L.H.: New class of carbonnanotube aerogel electrodes for electrochemical power sources. Adv. Mater. 20(4), 815-819 (2008)

101. De Marco, M., Markoulidis, F., Menzel, R., Bawaked, S.M., Mokhtar, M., Al-Thabaiti, S.A., Basahel, S.N., Shaffer, M.S.: Cross-linked single-walled carbon nanotube aerogel electrodes via reductive coupling chemistry. J. Mater. Chem. A 4(15), 53855389 (2016)

102. Li, Y., Kang, Z., Yan, X., Cao, S., Li, M., Guo, Y., Huan, Y., Wen, X., Zhang, Y.: A three-dimensional reticulate CNT-aerogel for a high mechanical flexibility fiber supercapacitor. Nanoscale 10(19), 9360-9368 (2018)

103. Allen, M.J., Tung, V.C., Kaner, R.B.: Honeycomb carbon: a review of graphene. Chem. Rev. 110(1), 132-145 (2009)

104. Worsley, M.A., Pauzauskie, P.J., Olson, T.Y., Biener, J., Satcher Jr., J.H., Baumann, T.F.: Synthesis of graphene aerogel with high electrical conductivity. J. Am. Chem. Soc. 132(40), 1406714069 (2010)

105. Xu, Y., Sheng, K., Li, C., Shi, G.: Self-assembled graphene hydrogel via a one-step hydrothermal process. ACS Nano 4(7), 4324-4330 (2010)

106. Zhang, X., Sui, Z., Xu, B., Yue, S., Luo, Y., Zhan, W., Liu, B.: Mechanically strong and highly conductive graphene aerogel and its use as electrodes for electrochemical power sources. J. Mater. Chem. 21(18), 6494-6497 (2011)

107. Shan, H., Xiong, D., Li, X., Sun, Y., Yan, B., Li, D., Lawes, S., Cui, Y., Sun, X.: Tailored lithium storage performance of graphene aerogel anodes with controlled surface defects for lithiumion batteries. Appl. Surf. Sci. 364, 651-659 (2016)

108. Manthiram, A., Fu, Y., Chung, S.-H., Zu, C., Su, Y.-S.: Rechargeable lithium-sulfur batteries. Chem. Rev. 114(23), 11751-11787 (2014)

109. Zhou, G., Paek, E., Hwang, G.S., Manthiram, A.: High-performance lithium-sulfur batteries with a self-supported, 3D Li2sdoped graphene aerogel cathodes. Adv. Energy Mater. 6(2), 1501355 (2016)

110. Enterría, M., Botas, C., Gómez-Urbano, J.L., Acebedo, B., del Amo, J.M.L., Carriazo, D., Rojo, T., Ortiz-Vitoriano, N.: Pathways towards high performance $\mathrm{Na}-\mathrm{O}_{2}$ batteries: tailoring graphene aerogel cathode porosity \& nanostructure. J. Mater. Chem. A 6(42), 20778-20787 (2018)

111. Fan, Q., Yang, M., Meng, Q., Cao, B., Yu, Y.: Activated-nitrogen-doped graphene-based aerogel composites as cathode materials for high energy density lithium-ion supercapacitor. J. Electrochem. Soc. 163(8), A1736-A1742 (2016)

112. Yang, Y., Liu, T., Zhu, X., Zhang, F., Ye, D., Liao, Q., Li, Y.: Boosting power density of microbial fuel cells with 3D nitrogen-doped graphene aerogel electrode. Adv. Sci. 3(8), 1600097 (2016)

113. Wang, X., Maeda, K., Thomas, A., Takanabe, K., Xin, G., Carlsson, J.M., Domen, K., Antonietti, M.: A metal-free polymeric photocatalyst for hydrogen production from water under visible light. Nat. Mater. 8(1), 76 (2009)

114. Shang, K., Yang, J.-C., Cao, Z.-J., Liao, W., Wang, Y.-Z., Schiraldi, D.A.: Novel polymer aerogel toward high dimensional stability, mechanical property, and fire safety. ACS Appl. Mater. Interfaces. 9(27), 22985-22993 (2017)

115. Meador, M.A.B., Alemán, C.R., Hanson, K., Ramirez, N., Vivod, S.L., Wilmoth, N., McCorkle, L.: Polyimide aerogels with amide cross-links: a low cost alternative for mechanically strong polymer aerogels. ACS Appl. Mater. Interfaces. 7(2), 1240-1249 (2015)

116. Randall, J.P., Meador, M.A.B., Jana, S.C.: Tailoring mechanical properties of aerogels for aerospace applications. ACS Appl. Mater. Interfaces. 3(3), 613-626 (2011)

117. Borghei, M., Miettunen, K., Greca, L.G., Poskela, A., Lehtonen, J., Lepikko, S., Tardy, B.L., Lund, P., Subramanian, V., Rojas, O.J.: Biobased aerogels with different surface charge as electrolyte carrier membranes in quantum dot-sensitized solar cell. Cellulose 25, 3363-3375 (2018)

118. Fu, Y., Wang, G., Mei, T., Li, J., Wang, J., Wang, X.: Accessible graphene aerogel for efficiently harvesting solar energy. ACS Sustain. Chem. Eng. 5(6), 4665-4671 (2017)

119. Mu, P., Bai, W., Zhang, Z., He, J., Sun, H., Zhu, Z., Liang, W., Li, A.: Robust aerogels based on conjugated microporous polymer nanotubes with exceptional mechanical strength for efficient solar steam generation. J. Mater. Chem. A 6(37), 18183-18190 (2018)

120. He, W., Zhang, X., Conducting polymer aerogels. In: Yilmaz F (ed.) Conducting Polymers. IntechOpen (2016). https://doi. org $/ 10.5772 / 61723$

121. Xu, Y., Sui, Z., Xu, B., Duan, H., Zhang, X.: Emulsion template synthesis of all conducting polymer aerogels with superb adsorption capacity and enhanced electrochemical capacitance. J. Mater. Chem. 22(17), 8579-8584 (2012)

122. Guo, H., He, W., Lu, Y., Zhang, X.: Self-crosslinked polyaniline hydrogel electrodes for electrochemical energy storage. Carbon 92, 133-141 (2015)

123. Heiligtag, F.J., Cheng, W., de Mendonça, V.R., Süess, M.J., Hametner, K., Günther, D., Ribeiro, C., Niederberger, M.: Selfassembly of metal and metal oxide nanoparticles and nanowires into a macroscopic ternary aerogel monolith with tailored photocatalytic properties. Chem. Mater. 26(19), 5576-5584 (2014)

124. Guo, Z., Chen, Y., Lu, N.L.: Multifunctional Nanocomposites for Energy and Environmental Applications. Wiley-VCH verlag GmbH\&Co, Weinheim, Germany (2018)

125. Alwin, S., Bhat, S., Sahu, A., Jalajakshi, A., Sridhar, P., Pitchumani, S., Shukla, A.: Modified-pore-filled-PVDF-membrane electrolytes for direct methanol fuel cells. J. Electrochem. Soc. 158(2), B91-B98 (2011)

126. Anderson, M.L., Stroud, R.M., Morris, C.A., Merzbacher, C.I., Rolison, D.R.: Tailoring advanced nanoscale materials through synthesis of composite aerogel architectures. Adv. Eng. Mater. 2(8), 481-488 (2000) 
127. Feinle, A., Hüsing, N.: Mixed metal oxide aerogels from tailormade precursors. J. Supercrit. Fluids 106, 2-8 (2015)

128. Gao, X.-D., Li, X.-M., Gan, X.-Y., Wu, Y.-Q., Zheng, R.-K., Wang, C.-L., Gu, Z.-Y., He, P.: Aerogel based $\mathrm{SiO}_{2}-\mathrm{TiO}_{2}$ hybrid photoanodes for enhanced light harvesting in dye-sensitized solar cells. J. Mater. Chem. 22(36), 18930-18938 (2012)

129. Gao, Y.P., Sisk, C.N., Hope-Weeks, L.J.: A sol-gel route to synthesize monolithic zinc oxide aerogels. Chem. Mater. 19(24), 6007-6011 (2007)

130. Alwin, S., Sahaya, X.S.: Facile synthesis of 3-D nanostructured zinc oxide aerogel and its application as photoanode material for dye-sensitized solar cells. Surf. Interfaces 7, 14-19 (2017)

131. Popa, M., Macovei, D., Indrea, E., Mercioniu, I., Popescu, I., Danciu, V.: Synthesis and structural characteristics of nitrogen doped TiO2 aerogels. Microporous Mesoporous Mater. 132(1-2), 80-86 (2010)

132. Asahi, R., Morikawa, T., Ohwaki, T., Aoki, K., Taga, Y.: Visible-light photocatalysis in nitrogen-doped titanium oxides. Science 293(5528), 269-271 (2001)

133. Correa Baena, J.P., Agrios, A.G.: Antimony-doped tin oxide aerogels as porous electron collectors for dye-sensitized solar cells. J. Phys. Chem. C 118(30), 17028-17035 (2014)

134. Bakhshayesh Sr., A.: $\mathrm{Zn}$ co-doped $\mathrm{TiO}_{2}$ xerogel film made of uniform spheres for high-performance dye-sensitized solar cells. J. Solid State Electrochem. 20(2), 389-400 (2016)

135. Beauger, C., Testut, L., Berthon-Fabry, S., Georgi, F., Guétaz, L.: Doped TiO2 aerogels as alternative catalyst supports for proton exchange membrane fuel cells: a comparative study of $\mathrm{Nb}, \mathrm{V}$ and Ta dopants. Microporous Mesoporous Mater. 232, 109-118 (2016)

136. Lin, C.-C., Wei, T.-Y., Lee, K.-T., Lu, S.-Y.: Titania and Pt/ titania aerogels as superior mesoporous structures for photocatalytic water splitting. J. Mater. Chem. 21(34), 12668-12674 (2011)

137. DeSario, P.A., Pietron, J.J., DeVantier, D.E., Brintlinger, T.H., Stroud, R.M., Rolison, D.R.: Plasmonic enhancement of visible-light water splitting with $\mathrm{Au}-\mathrm{TiO}_{2}$ composite aerogels. Nanoscale 5(17), 8073-8083 (2013)

138. Puskelova, J., Baia, L., Vulpoi, A., Baia, M., Antoniadou, M., Dracopoulos, V., Stathatos, E., Gabor, K., Pap, Z., Danciu, V.: Photocatalytic hydrogen production using TiO2-Pt aerogels. Chem. Eng. J. 242, 96-101 (2014)

139. Fort, C., Pap, Z., Indrea, E., Baia, L., Danciu, V., Popa, M.: Pt/N$\mathrm{TiO}_{2}$ aerogel composites used for hydrogen production via photocatalysis process. Catal. Lett. 144(11), 1955-1961 (2014)

140. Inonu, Z., Keskin, S., Erkey, C.: An emerging family of hybrid nanomaterials: metal-organic framework/aerogel composites. ACS Appl. Nano Mater. 1(11), 5959-5980 (2018)

141. Alwin, S., Ramasubbu, V., Shajan, X.S.: TiO_2 aerogel-metal organic framework nanocomposite: a new class of photoanode material for dye-sensitized solar cell applications. Bull. Mater. Sci. 41(1), 27 (2018)

142. Ramasubbu, V., Alwin, S., Mothi, E., Shajan, X.S.: TiO2 aerogel-Cu-BTC metal-organic framework composites for enhanced photon absorption. Mater. Lett. 197, 236-240 (2017)

143. Lu, S., Guo, H., Zhou, Y., Liu, Y., Jin, Z., Liu, B., Zhao, Y., in: AIP Conference Proceedings, AIP Publishing, p. 030004 (2017)

144. Moreno-Castilla, C., Maldonado-Hódar, F.: Carbon aerogels for catalysis applications: an overview. Carbon 43(3), 455-465 (2005)

145. Lee, Y.J., Park, S., Seo, J.G., Yoon, J.R., Yi, J., Song, I.K.: Nanosized metal-doped carbon aerogel for pseudo-capacitive supercapacitor. Curr. Appl. Phys. 11(3), 631-635 (2011)

146. Lee, Y.J., Jung, J.C., Park, S., Seo, J.G., Baeck, S.-H., Yoon, J.R., Yi, J., Song, I.K.: Preparation and performance of cobalt-doped carbon aerogel for supercapacitor. Korean J. Chem. Eng. 28(2), 492-496 (2011)

147. Gigot, A., Fontana, M., Pirri, C., Rivolo, P.: Graphene/ruthenium active species aerogel as electrode for supercapacitor applications. Materials 11(1), 57 (2017)

148. Abdelwahab, A., Castelo-Quibén, J., Vivo-Vilches, J., PérezCadenas, M., Maldonado-Hódar, F., Carrasco-Marín, F., PérezCadenas, A.: Electrodes based on carbon aerogels partially graphitized by doping with transition metals for oxygen reduction reaction. Nanomaterials 8(4), 266 (2018)

149. Tesfaye, R.M., Das, G., Park, B.J., Kim, J., Yoon, H.H.: Ni-Co bimetal decorated carbon nanotube aerogel as an efficient anode catalyst in urea fuel cells. Sci. Rep. 9(1), 479 (2019)

150. Liu, T., Kou, T., Bulmahn, D., Ortuno-Quintana, C., Liu, G., Lu, J.Q., Li, Y.: Tuning the electrochemical properties of nitrogendoped carbon aerogels in a blend of ammonia and nitrogen gases. ACS Appl. Energy Mater. 1(9), 5043-5053 (2018)

151. Zeng, F.-Y., Sui, Z.-Y., Liu, S., Liang, H.-P., Zhan, H.-H., Han, B.-H.: Nitrogen-doped carbon aerogels with high surface area for supercapacitors and gas adsorption. Mater. Today Commun. 16, 1-7 (2018)

152. Wei, X., Wan, S., Gao, S.: Self-assembly-template engineering nitrogen-doped carbon aerogels for high-rate supercapacitors. Nano Energy 28, 206-215 (2016)

153. Sui, Z.-Y., Meng, Y.-N., Xiao, P.-W., Zhao, Z.-Q., Wei, Z.-X., Han, B.-H.: Nitrogen-doped graphene aerogels as efficient supercapacitor electrodes and gas adsorbents. ACS Appl. Mater. Interfaces. 7(3), 1431-1438 (2015)

154. Seredych, M., László, K., Bandosz, T.J.: Sulfur-doped carbon aerogel as a metal-free oxygen reduction catalyst. ChemCatChem 7(18), 2924-2931 (2015)

155. Tang, Z., Jiang, J., Liu, S., Chen, L., Liu, R., Zheng, B., Fu, R., $\mathrm{Wu}, \mathrm{D}$.: Polyaniline-coated activated carbon aerogel/sulfur composite for high-performance lithium-sulfur battery. Nanoscale Res. Lett. 12(1), 617 (2017)

156. Yin, H., Zhang, C., Liu, F., Hou, Y.: Hybrid of iron nitride and nitrogen-doped graphene aerogel as synergistic catalyst for oxygen reduction reaction. Adv. Funct. Mater. 24(20), 2930-2937 (2014)

157. Kalpana, D., Omkumar, K., Kumar, S.S., Renganathan, N.: A novel high power symmetric $\mathrm{ZnO} /$ carbon aerogel composite electrode for electrochemical supercapacitor. Electrochim. Acta 52(3), 1309-1315 (2006)

158. Sun, G., Xie, H., Ran, J., Ma, L., Shen, X., Hu, J., Tong, H.: Rational design of uniformly embedded metal oxide nanoparticles into nitrogen-doped carbon aerogel for high-performance asymmetric supercapacitors with a high operating voltage window. J. Mater. Chem. A 4(42), 16576-16587 (2016)

159. Nichelson, A., Karthickprabhu, S., Karuppasamy, K., Hirankumar, G., Sahaya Shajan, X.: A brief review on integrated (layered and spinel) and olivine nanostructured cathode materials for lithium ion battery applications. Mater. Focus 5(4), 324-334 (2016)

160. Jiang, J., Li, Y., Liu, J., Huang, X., Yuan, C., Lou, X.W.: Recent advances in metal oxide-based electrode architecture design for electrochemical energy storage. Adv. Mater. 24(38), 5166-5180 (2012)

161. Chen, Z., Li, H., Tian, R., Duan, H., Guo, Y., Chen, Y., Zhou, J., Zhang, C., Dugnani, R., Liu, H.: Three dimensional Graphene aerogels as binder-less, freestanding, elastic and high-performance electrodes for lithium-ion batteries. Sci Rep 6, 27365 (2016)

162. Zeng, G., Shi, N., Hess, M., Chen, X., Cheng, W., Fan, T., Niederberger, M.: A general method of fabricating flexible spineltype oxide/reduced graphene oxide nanocomposite aerogels 
as advanced anodes for lithium-ion batteries. ACS Nano 9(4), 4227-4235 (2015)

163. Sun, X., Zhu, X., Yang, X., Sun, J., Xia, Y., Yang, D.: CoFe2O4/ carbon nanotube aerogels as high performance anodes for lithium ion batteries. Green Energy Environ. 2(2), 160-167 (2017)

164. Che, Y., Zhu, X., Li, J., Sun, J., Liu, Y., Jin, C., Dong, C.: Simple synthesis of $\mathrm{MoO}_{2} /$ carbon aerogel anodes for high performance lithium ion batteries from seaweed biomass. Rsc Ad. 6(108), 106230-106236 (2016)

165. Li, X., Zhao, K., Zhang, L., Ding, Z., Hu, K.: $\mathrm{MoS}_{2}$-decorated coaxial nanocable carbon aerogel composites as cathode materials for high performance lithium-sulfur batteries. J. Alloys Compd. 692, 40-48 (2017)

166. Liu, T., Mai, X., Chen, H., Ren, J., Liu, Z., Li, Y., Gao, L., Wang, N., Zhang, J., He, H.: Carbon nanotube aerogel-CoS 2 hybrid catalytic counter electrodes for enhanced photovoltaic performance dye-sensitized solar cells. Nanoscale 10(9), 4194-4201 (2018)

167. Ye, Y., Bindl, D.J., Jacobberger, R.M., Wu, M.Y., Roy, S.S., Arnold, M.S.: Semiconducting carbon nanotube aerogel bulk heterojunction solar cells. Small 10(16), 3299-3306 (2014)

168. Wu, L., Zhang, Y., Li, B., Wang, P., Fan, L., Zhang, N., Sun, K.: Fabrication of layered structure VS 4 anchor in 3D graphene aerogels as a new cathode material for lithium ion batteries. Front. Energy 13(3), 597-602 (2019)

169. Zhang, J., Xia, Z., Dai, L.: Carbon-based electrocatalysts for advanced energy conversion and storage. Sci. Adv. 1(7), e1500564 (2015)

170. Fu, G., Liu, Y., Chen, Y., Tang, Y., Goodenough, J.B., Lee, J.-M.: Robust $\mathrm{N}$-doped carbon aerogels strongly coupled with ironcobalt particles as efficient bifunctional catalysts for rechargeable Zn-air batteries. Nanoscale 10(42), 19937-19944 (2018)
171. Zhang, L., Yang, X., Cai, R., Chen, C., Xia, Y., Zhang, H., Yang, D., Yao, X.: Air cathode of zinc-air batteries: a highly efficient and durable aerogel catalyst for oxygen reduction. Nanoscale 11(3), 826-832 (2019)

172. An, H., Wang, Y., Wang, X., Zheng, L., Wang, X., Yi, L., Bai, L., Zhang, X.: Polypyrrole/carbon aerogel composite materials for supercapacitor. J. Power Sources 195(19), 6964-6969 (2010)

173. Ouyang, A., Cao, A., Hu, S., Li, Y., Xu, R., Wei, J., Zhu, H., Wu, D.: Polymer-coated graphene aerogel beads and supercapacitor application. ACS Appl. Mater. Interfaces. 8(17), 11179-11187 (2016)

174. Crane, M.J., Lim, M.B., Zhou, X., Pauzauskie, P.J.: Rapid synthesis of transition metal dichalcogenide-carbon aerogel composites for supercapacitor electrodes. Microsyst. Nanoeng. 3, 17032 (2017)

175. Chen, Z., Hsu, P.-C., Lopez, J., Li, Y., To, J.W., Liu, N., Wang, C., Andrews, S.C., Liu, J., Cui, Y.: Fast and reversible thermoresponsive polymer switching materials for safer batteries. Nat. Energy 1(1), 15009 (2016)

176. Shi, Y., Ha, H., Al-Sudani, A., Ellison, C.J., Yu, G.: Thermoplastic elastomer-enabled smart electrolyte for thermoresponsive self-protection of electrochemical energy storage devices. Adv. Mater. 28(36), 7921-7928 (2016)

177. Shi, Y., Ma, C., Peng, L., Yu, G.: Conductive "smart" hybrid hydrogels with PNIPAM and nanostructured conductive polymers. Adv. Funct. Mater. 25(8), 1219-1225 (2015)

Publisher's Note Springer Nature remains neutral with regard to jurisdictional claims in published maps and institutional affiliations. 